\title{
Análise dos elementos estruturais de metaloproteinases das classes P-I e P-III do veneno de Bothrops jararaca importantes para suas interações com proteínas plasmáticas e da matriz extracelular.
}

\section{ANA KARINA DE OLIVEIRA}

Dissertação apresentada ao Programa de PósGraduação Interunidades em Biotecnologia USP / Instituto Butantan / IPT, para obtenção do título de Mestre em Biotecnologia.

Área de concentração: Biotecnologia

Orientadora: Dra Solange Maria de Toledo Serrano 


\section{RESUMO}

OLIVEIRA, A. K. Análise dos elementos estruturais de metaloproteinases das classes P-I e P-III do veneno de Bothrops jararaca importantes para suas interações com proteínas plasmáticas e da matriz extracelular. $130 \mathrm{f}$. Dissertação (Mestrado em Biotecnologia) - Instituto de Ciências Biomédicas, Universidade de São Paulo, São Paulo, 2009.

A hemorragia local, desencadeada por metaloproteinases presentes nos venenos de serpentes, é uma das características mais importantes do envenenamento. Diversos trabalhos têm mostrado que há uma interação específica entre as metaloproteinases e seus substratos, sejam estes proteínas relacionadas com a hemostasia ou proteínas da matriz extracelular. O que ainda não está claro é o modo como estas proteinases interagem com cada substrato e de que forma a proteólise está relacionada com a hemorragia local observada. Para melhor entender a importância dos elementos estruturais destas proteinases na interação com seus substratos protéicos, realizamos um estudo comparativo com metaloproteinases do veneno da Bothrops jararaca. Para isso isolamos uma nova proteinase da classe P-I, que possui apenas o domínio catalítico e não causa hemorragia com doses de até $20 \mu \mathrm{g}$, denominada BJ-PI; duas metaloproteinases já caracterizadas da classe P-III, HF3 e bothropasina, que causam hemorragia local com diferentes doses mínimas hemorrágicas, e que possuem, além do domínio catalítico, os domínios tipodisintegrina e rico em cisteínas (DC); e ainda uma proteína composta pelos domínios DC gerada pela autólise de metaloproteinases no veneno. A comparação da atividade proteolítica destas proteinases sobre a caseína e sobre o fibrinogênio mostrou que a bothropasina e a BJ-PI têm altas atividades específicas sobre esses substratos, enquanto que o HF3 é muito menos ativo. Contudo, em ensaios de ligação em fase sólida o HF3 e a bothropasina ligaram-se de forma dosedependente e em concentrações semelhantes ao fibrinogênio, fibronectina e ao colágeno $\mathrm{Vl}$; ao colágeno I e à laminina estas proteinases também se ligaram, porém com afinidades diferentes. A proteína DC se ligou aos colágenos I e VI, ainda que em concentrações maiores do que as proteinases da classe P-III, mas não à fibronectina. Nos ensaios com a BJ-PI não foi detectada sua interação com nenhum 
dos substratos testados. Para avaliação do papel de carboidratos presentes nas estruturas das proteinases, estas foram submetidas à $\mathrm{N}$-deglicosilação em condições não desnaturantes. O HF3 foi parcialmente deglicosilado, o que levou à perda parcial de suas atividades hemorrágica e fibrinogenolítica, enquanto que a bothropasina e a BJ-PI perderam sua integridade estrutural e atividade enzimática. Em ensaios de ressonância plasmônica de superfície, onde foram imobilizados colágeno I e VI, o HF3 deglicosilado ligou-se com maior afinidade aos substratos quando comparado com a proteinase nativa, diferentemente da bothropasina deglicosilada que interagiu com afinidade reduzida. Em conjunto, estes resultados sugerem que as porções glicosídicas presentes nas metaloproteinases são importantes para manter sua integridade estrutural, além de estarem envolvidas nas interações com seus substratos. Ainda, os domínios não catalíticos do HF3 e da bothropasina devem estar envolvidos no direcionamento destas proteinases aos seus alvos protéicos in vivo, em contraste com a BJ-PI que não apresenta atividade hemorrágica, e não mostrou interação com nenhum substrato testado, apesar de apresentar atividade proteolítica sobre vários substratos in vitro.

Palavras-chave: Serpentes. Veneno. Metaloproteinases. Matriz extracelular. Plasma. Hemorragia. 


\section{ABSTRACT}

OLIVEIRA, A. K. Analysis of the structural requirements for the interaction of P-I and P-III class metalloproteinases from Bothrops jararaca venom with plasma and extracellular matrix proteins. $130 \mathrm{f}$. Master thesis (Biotechnology) - Instituto de Ciências Biomédicas, Universidade de São Paulo, São Paulo, 2009.

Local hemorrhage induced by snake venom metalloproteinases is one of the main features of viperid envenoming. Many studies have shown the specific interaction of metalloproteinases and proteins of the hemostatic system and of the extracellular matrix. However, the mechanisms of interaction between venom metalloproteinases and their natural substrates and the correlation between proteolysis and hemorrhage are not completely understood. In order to better understand the structural requirements for the interaction of venom metalloproteinases and their substrates we carried out a comparative study of Bothrops jararaca venom enzymes. For this purpose we isolated a new P-I class metalloproteinase, named BJ-PI, which contains only the catalytic domain and is devoid of hemorrhagic activity with doses of up to 20 $\mu \mathrm{g}$; HF3 and bothropasin are hemorrhagic metalloproteinases that contain catalytic, disintegrin-like and cysteine-rich domains (DC); and a protein generated by the autolysis of metalloproteinases in the venom and composed of the DC domains. Bothropasin and BJ-PI showed high specific caseinolytic and fibrinogenolytic activities while HF3 was rather weakly active upon these proteins. However, solidphase binding assays showed the binding of HF3 and bothropasin to fibrinogen, fibronectin and collagen $\mathrm{VI}$ in a dose-dependent fashion and at similar concentrations. These proteinases also bound to collagen I and laminin however with different affinity levels. Although at higher concentrations, the DC protein showed interaction to collagens I and VI, but it did not interact with fibronectin. On the other hand, BJ-PI did not show interaction to any of the tested substrates. We next evaluated the role of the carbohydrate moiety in the structure and activity of the proteinases by submitting the proteins to $\mathrm{N}$-deglycosylation under non-denaturating conditions. The partial deglycosylation of HF3 caused loss of part of its hemorrhagic and fibrinogenolytic activities. However, deglycosylated bothropasin and BJ-PI lost both structural integrity and proteolytic activities. Moreover, in surface plasmon 
resonance assays partially deglycosylated HF3 bound with higher affinity to immobilized collagens $I$ and VI than the native protein, while deglycosylated bothropasin interacted with the collagens with much lower affinity. Taken together, these results suggest that the carbohydrate moiety of venom metalloproteinases play an important role in the maintenance of their structural integrity, and are involved in the interaction with their substrates. Furthermore, the non-catalytic domains of HF3 and bothropasin likely function to target these toxins to key substrates in vivo. In contrast, BJ-PI, which does not contain non-catalytic domains, is highly caseinolytic but not hemorrhagic, and did not show any detectable interaction to its in vitro substrates.

Key words: Snake. Venom. Metalloproteinase. Extracellular matrix. Plasma. Hemorrhage. 


\section{INTRODUÇÃO}

A principal função dos venenos de serpentes é a paralisação e digestão da presa. As enzimas presentes no veneno dão inicio à digestão dos tecidos e a morte da presa é devida às falhas respiratórias ou circulatórias causadas por várias neurotoxinas, cardiotoxinas, enzimas coagulantes e outros componentes que agem isoladamente ou em sinergia. Deste modo, os venenos contêm substâncias destinadas a afetar processos vitais, atuando nos sistemas cardiovascular, nervoso, locomotor, hemostático, e interferem na migração e sinalização celular e na permeabilidade de membranas (KARLSSON, 1979).

Os sintomas do envenenamento por serpentes viperídeas dependem da complexidade do veneno e da quantidade inoculada, e em geral, são caracterizados por um importante efeito local, incluindo edema inflamatório, dor, hemorragia e necrose tecidual, com evolução rápida, e que, muitas vezes podem deixar seqüelas (GUTIÉRREZ e LOMONTE, 1989); no envenenamento podem também ocorrer alterações sistêmicas como hemorragia em órgãos distantes da lesão inicial, (coração, pulmão, rins e cérebro), agregação de plaquetas, coagulação intravascular, hipotensão, insuficiência respiratória e choque, levando algumas vezes ao óbito (BJARNASON e FOX, 1988; RIBEIRO et al., 1998).

A intensa hemorragia local é uma das principais características do envenenamento, e que em casos graves, pode chegar a ser sistêmica (OUYANG et al., 1992; BJARNASON e FOX, 1995; KAMIGUTI et al., 1996). Os venenos de serpentes viperídeas são ricos em toxinas hemorrágicas, caracterizadas como metaloproteinases que contêm zinco no sítio ativo (BJARNASON e FOX, 1995).

Considerando a grande quantidade de metaloproteinases que compõem os venenos de serpentes, principalmente o da B. jararaca, que contem cerca de $50 \%$ de metaloproteinase, segundo análises transcriptômica e proteômica (FOX e SERRANO, 2008a), elucidar os mecanismos envolvidos na geração de hemorragia por estas enzimas contribuiria, não só na assistência às vítimas de envenenamento, como também na compreensão dos mecanismos de interação entre metaloproteinases de mamíferos e seus substratos em condições fisiológicas e patológicas. 


\subsection{Enzimas Proteolíticas}

Antigamente as enzimas proteolíticas, endoproteinases ou peptidases eram classificadas de acordo com sua especificidade pelo substrato, carga e peso molecular. Atualmente este sistema de classificação está baseado na comparação do mecanismo de catálise, nos resíduos envolvidos na catálise e na estrutura tridimensional da proteína. De acordo com os resíduos peptídicos envolvidos na catálise, as enzimas proteolíticas são agrupadas em famílias: serinoproteinases, cisteinoproteinases, aspartilproteinases, treoninoproteinases, glutamilproteinases, metaloproteinases e ainda encontramos um grupo de proteinases onde os resíduos envolvidos na catálise são desconhecidos (BARRETT et al., 1998; RAWLINGS et al., 2008).

Estas famílias são subdivididas em clãs de acordo com sua origem evolutiva, estrutura terciária, ou ainda pela presença de seqüências conservadas próximas ao sítio catalítico. Estes clãs são representados por letras, sendo que a primeira representa o tipo de catalisador (BARRETT et al., 1998; RAWLINGS et al., 2008). Ao clã MA pertencem as famílias das astacinas, serralisinas, matrixinas e adamalisinas/reprolisinas, entre outras (figura 1).

As subfamílias M10A e M12B, que pertencem ao clã MA, apresentam seqüência consenso estendida $\mathbf{H}-\mathbf{E}-\mathbf{X}-\mathbf{X}-\mathbf{H}-\mathbf{X}-\mathbf{X}-\mathbf{G}-\mathbf{X}-\mathbf{X}-\mathbf{H}$......M, em que $0 \quad \mathbf{X}$ representa qualquer resíduo de aminoácido, as três histidinas são ligantes do átomo de zinco, e o ácido glutâmico, têm função catalítica (BARRETT et al., 1998; RAWLINGS et al., 2008). O resíduo $\mathrm{M}$ (metionina) é um resíduo conservado distante do motif de ligação do átomo de zinco, e faz parte do Met-turn formado pela seqüência $\mathbf{C}(\mathbf{I} / \mathbf{V}) \mathbf{M}$, onde a metionina forma uma base hidrofóbica para o átomo de zinco e os três resíduos de histidina do sítio catalítico (BODE et al., 1993; STÖCKER e BODE, 1995).

As enzimas proteolíticas das subfamílias M10A e M12B são sintetizadas como pró-enzimas inativas (zimogênio); estas enzimas possuem uma seqüência consenso conservada, PRㅡG(V/N)PD e PKMㅡGVT, respectivamente, que se encontram no pró-domínio, localizada cerca de vinte posições antes do resíduo $\mathrm{N}$ terminal do domínio catalítico. A cisteína desta seqüência interage com o átomo de zinco, impedindo a ligação de uma molécula de água ou de um substrato ao sítio 
ativo, inibindo a função proteolítica da enzima; este mecanismo é conhecido como "cysteine-switch" (GRAMS et al., 1993; BODE, et al. 1993). Após a definição de estrutura cristalográfica da VAP1 (Vascular Apoptosis-Inducing Protein 1), uma metaloproteinase homodimérica da classe P-Illc do veneno de Crotalus atrox, foram determinados, além do sítio de ligação do átomo de zinco, três sítios de ligação para íons $\mathrm{Ca}^{2+}$ na molécula (TAKEDA et al., 2006).

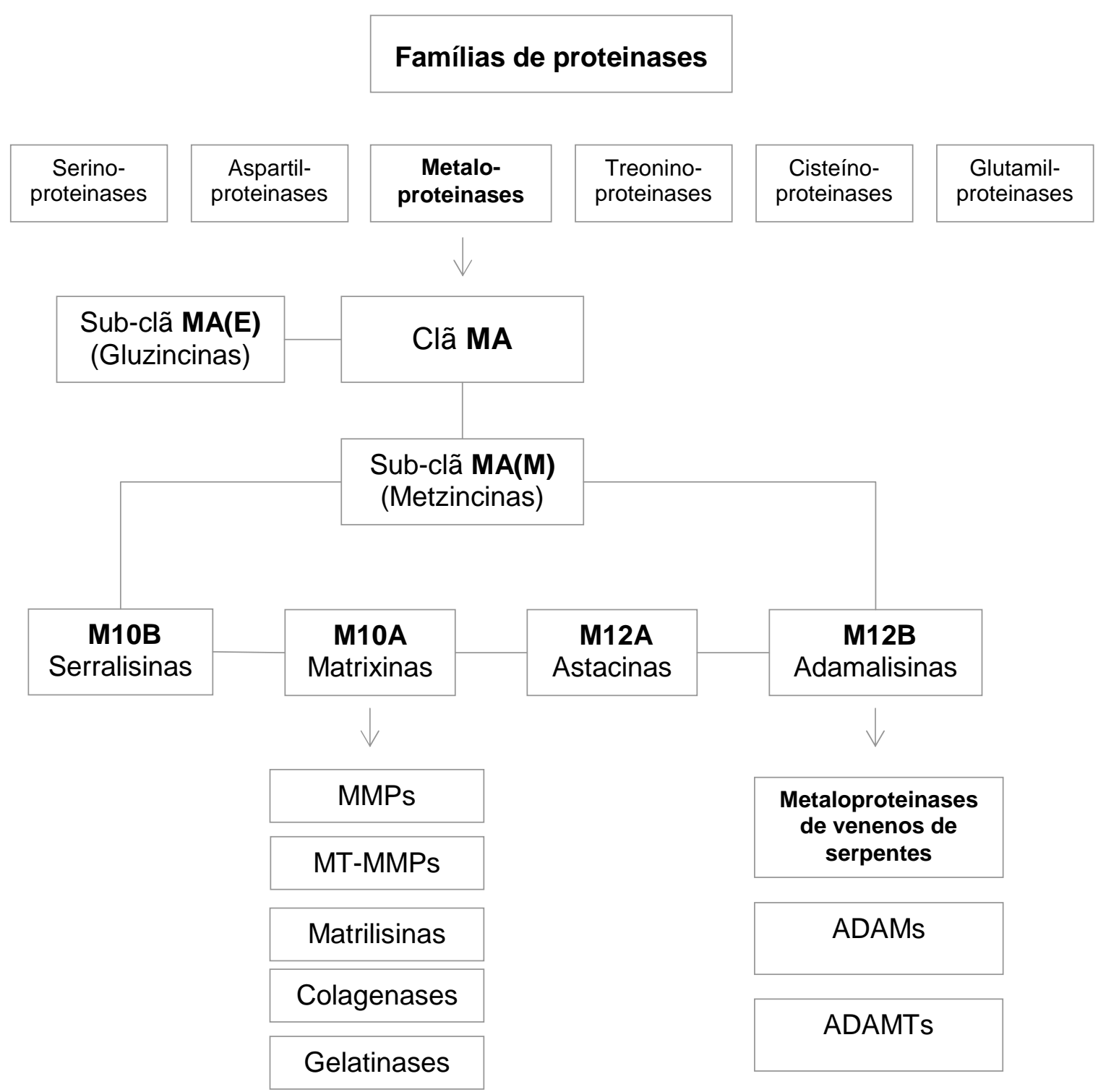

Figura 1. Esquema de classificação das enzimas proteolíticas, com destaque para algumas famílias de metaloproteinases.

FONTE: Adaptado Rawlings et al., (2008). 
A família das adamalisinas, também conhecidas como reprolisinas, é composta por proteínas modulares que possuem alguns domínios homólogos entre si, como o domínio catalítico, o tipo disintegrina e o rico em cisteínas, e é formada pelas ADAMs (a disintegrin and metalloproteinase), as ADAMTSs (a disintegrin and metalloproteinase with thrombospondin motifs) que são expressas em mamíferos, e as metaloproteinases de veneno de serpentes. O termo reprolisina foi introduzido por Bjarnason e Fox (1995) para designar as metaloproteinases que pertencem à sub-família M12B da família M12A (astacina), formada por proteinases que são mais parecidas entre si do que com os membros da família astacina propriamente dita. $A$ palavra reprolisina reflete o fato de que muitos dos trabalhos sobre estas enzimas foram feitos com enzimas isoladas de venenos de serpentes (réptil), embora alguns dos membros dessa família sejam proteínas do tecido reprodutivo.

\subsection{ADAMs e ADAMTSs}

As ADAMs formam uma família de proteinases transmembrânicas, de estrutura modular caracterizada pela presença dos domínios catalítico, disintegrina, rico em cisteínas, EGF (fator de crescimento epidérmico), transmembrânico e citoplasmático (figura 2). A esta família pertence um grupo de proteínas de superfície celular, que combinam tanto a característica de molécula de adesão de superfície celular como também de proteinase (WOLFSBERG e WHITE, 1996). Estas proteinases desempenham importante papel em diversos processos fisiológicos como: inflamação, mitogênese, angiogênese, reprodução, proteólise, adesão, sinalização (ANDREWS e BERNDT, 2000), e modula processos biológicos tais como migração e crescimento celular (ALFANDARI et al., 2001).

A fertilização do óvulo pelo espermatozóide é iniciada pela união de duas células e a fusão de suas membranas. As ADAMs 1 e 2 (originalmente chamadas de fertilina $\alpha$ e $\beta$ ) estão envolvidas neste processo (SEALS e COURTNEIDGE, 2003). Durante a maturação do esperma no testículo e no epidídimo, as ADAMs 1 e 2 são processadas proteoliticamente e seus pró-domínios e domínios catalíticos removidos, resultando em uma ADAM heterodimérica com o domínio tipo 
disintegrina na porção $\mathrm{N}$-terminal em ambas subunidades. Há indícios de que o domínio tipo disintegrina da ADAM2 interage com a integrina $\alpha_{6} \beta_{1}$ (receptor para os espermatozóides, presente nos óvulos) (SCHLÖNDORFF e BLOBEL, 1999). A ADAM 3 também está envolvida em processos de fertilização; esta proteinase está presente na superfície da membrana dos espermatozóides (NISHIMURA et al., 2001), assim como as ADAMs 5 e 7, que também estão envolvidas na fertilização (KIM et al., 2006).

As células têm a capacidade de modificar a superfície plasmática, tanto no desenvolvimento quanto na maturidade celular, regulando varias funções. As citocinas ancoradas na membrana, fatores de crescimento, receptores, moléculas de adesão e enzimas são clivados e liberados das membranas plasmáticas por várias proteinases, denominadas sheddases ou secretases (HOOPER et al., 1997). Algumas destas sheddases podem ser ADAMs, como a ADAM17, que libera o fator de necrose tumoral TNF- $\alpha$ (BLACK et al., 1997).

Em processos inflamatórios ocorre a liberação do fator de necrose tumoral (TNF- $\alpha$ ), que é sintetizado como proteína de membrana ancorada ( 26 kDa) de onde o domínio extracelular ativo $(17 \mathrm{kDa})$ é liberado proteoliticamente por uma enzima conversora de TNF- $\alpha$ (TACE ou ADAM17); este é um dos fenômenos de shedding mais estudado. A TACE já foi purificada e clonada de monócitos de baço de boi, de porco e do homem. Uma série de estudos demonstrou a função sheddase das ADAMs (ADAM9 e ADAM17) (IZUMI et al., 1998; MOSS et al., 1997).

As ADAMTSs são proteinases formadas por seis domínios: pró-, catalítico, tipo disintegrina, trombospondina (TSP) tipo I, rico em cisteínas, região espaçadora, e um número variável de submotifs TSP tipo I na região C-terminal (figura 2). Algumas ADAMTSs também apresentam alguns domínios especiais como PLAC e CUB (FOX e SERRANO, 2005). Uma importante diferença entre as ADAMs e as ADAMTSs é a localização no tecido, as ADAMs são proteínas transmembrânicas e enquanto as ADAMTSs são solúveis.

As ADAMTSs têm atividades biológicas em diversos processos, tais como: 0 processamento do pró-colágeno (N-proteinase); degradação de proteoglicanos da matriz (agrecano, versicano e brevicano); inibição da angiogênese; coagulação sangüínea, fertilidade e inflamação (PORTER et al, 2005). Estas proteinases foram encontradas tanto em mamíferos quanto em invertebrados. Em humanos já foram 
descritos 19 genes para ADAMTS, além de três membros de uma subfamília chamada ADAMTSL (ADAMTS-like), que possui alguns domínios iguais aos das ADAMTSs (PORTER et al, 2005).

As ADAMTS 2, 3 e 14 são N-proteinases envolvidas na remoção dos própeptídeos da região N-terminal dos colágenos (COLIGE et al., 1995; FERNANDES et al., 2001; WANG et al., 2003). As ADAMTS 1, 4 e 5 são responsáveis pela degradação do agrecano, um dos maiores proteoglicanos de cartilagem e possivelmente associado com algumas formas de artrite (TORTORELLA et al., 2001). A ADAMTS 13 tem um importante papel na hemostasia modulando 0 tamanho dos multímeros do fator von Willebrand ( $V W F$ ), uma glicoproteína multimérica presente no plasma e envolvida na agregação plaquetária (SOEJIMA et al., 2001). A deficiência de ADAMTS 13 causa um distúrbio patológico conhecido como púrpura trombocitopênica trombótica (PTT); os grandes multímeros do fator von Willebrand induziriam a agregação plaquetária formando pequenos coágulos sangüíneos, levando a uma redução acentuada da quantidade de plaquetas e de eritrócitos no plasma (LEVY et al.,2001).

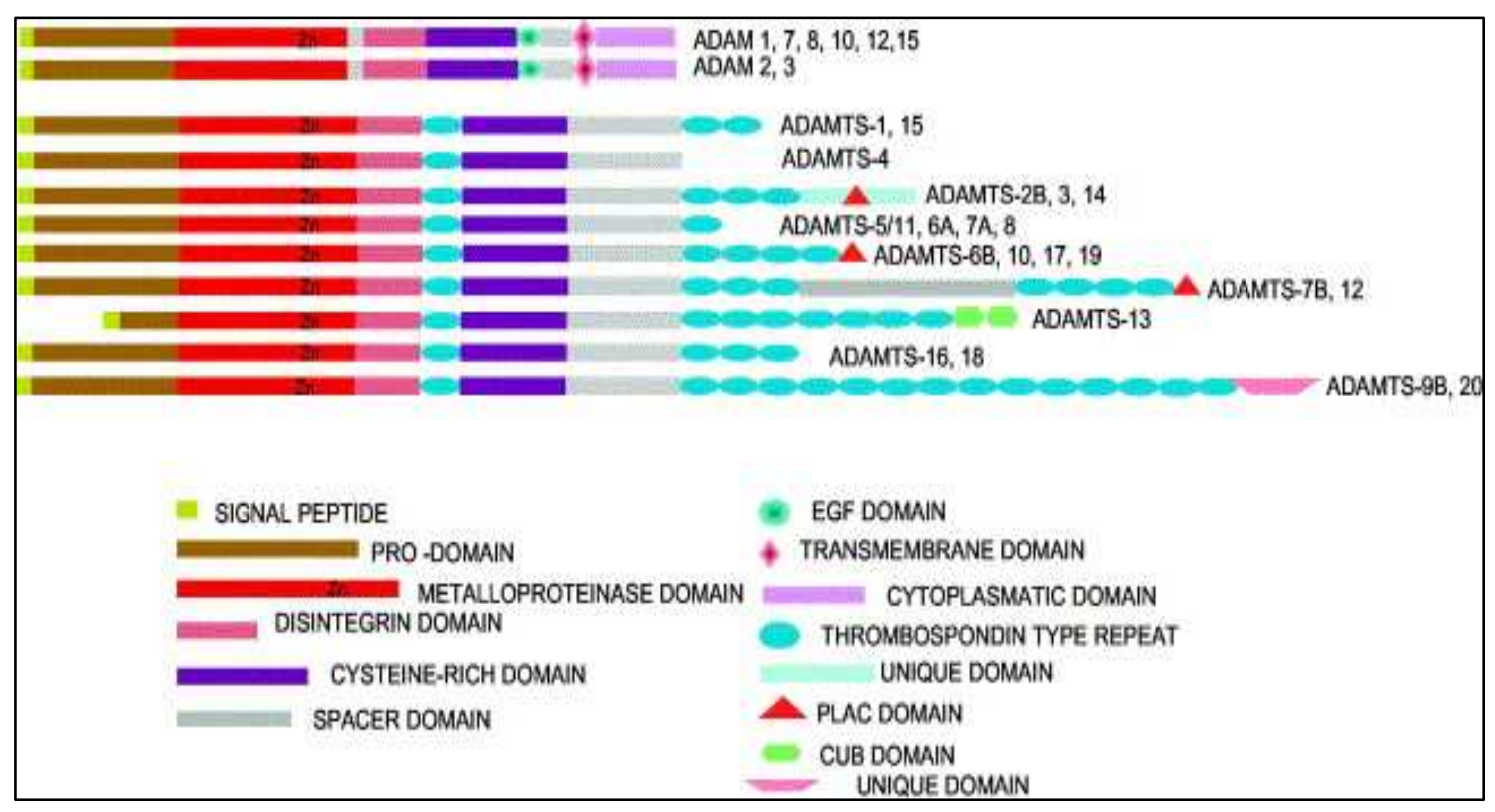

Figura 2. Estrutura esquemática dos domínios das ADAMs e ADAMTSs.

FONTE: Fox e Serrano, (2005). 


\subsection{Metaloproteinases de venenos de serpentes}

A partir de 1990, com a determinação das primeiras seqüências de cDNA de algumas metaloproteinases de venenos, foi possível realizar uma classificação estrutural detalhada (FOX e SERRANO, 2009). Essencialmente observaram-se diferenças de tamanho entre elas e a presença de diferentes domínios estruturais (BJARNASON e FOX, 1995).

As metaloproteinases de venenos foram então organizadas de acordo com seus domínios estruturais em quatro classes básicas: P-I, P-II, P-III e P-IV, baseando-se na seqüência de aminoácidos e $\mathbf{N}-\mathbf{I}, \mathbf{N}-\mathbf{I I}, \mathbf{N}-\mathbf{I I I}$, e $\mathbf{N}-\mathbf{I V}$, de acordo com as seqüências de seus cDNAs (BJARNASON e FOX, 1995).

Recentemente uma nova classificação foi proposta baseando-se nas características dos precursores das metaloproteinases de venenos, bem como nos produtos gerados a partir desses precursores após modificações pós-traducionais durante o processo de síntese. Nesta classificação a classe P-IV foi incorporada na classe P-Illd, considerando-se que, até agora, nenhum precursor específico contendo todos os domínios presentes nessas proteinases (catalítico, tipodisintegrina, rico em cisteínas e tipo-lectina) foi descrito, indicando que as proteinases que apresentam essa estrutura são geradas por modificações póstraducionais de um precursor da classe P-III (figura 3) (FOX e SERRANO, 2008b).

A biossíntese dos venenos de serpentes ocorre em glândulas especializadas, onde a maioria das proteínas secretadas é sintetizada no citoplasma de células secretoras. Estas proteínas são transferidas para o retículo endoplasmático rugoso, onde perdem o peptídeo sinal e assumem sua forma protéica através da formação de pontes de dissulfeto, glicosilações e multimerizações, como a dimerização de disintegrinas (P-IId/P-Ile) e adição de domínios tipo-lectina (P-IIld). No complexo de Golgi estas proteínas são transportadas em vesículas até o lúmen das glândulas secretoras (WARSHAWSKY et al., 1973; FOX e SERRANO, 2008b), onde a acidificação do meio, a presença de citrato (ODELL et al., 1998) e de um tripeptídeo pyrol-glutamato (ROBEVA et al., 1991; HUANG et al., 1998; MARQUES-PORTO et al., 2008) provavelmente inibem a atividade proteolítica destas enzimas no lúmen glandular mantendo a integridade celular e das proteínas do veneno. 


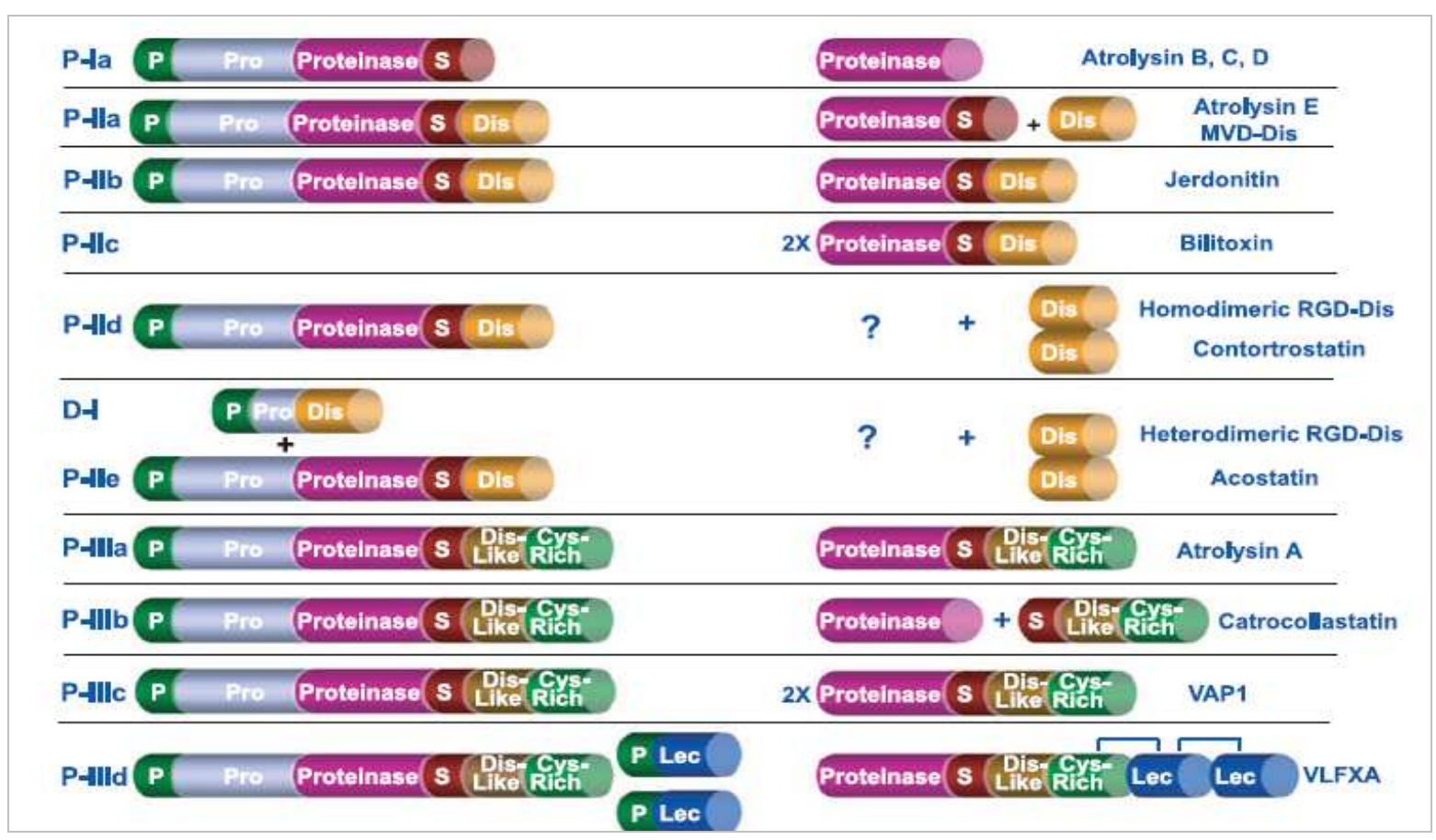

Figura 3. Esquema de classificação das metaloproteinases de venenos de serpentes.

FONTE: Fox e Serrano, (2008b).

Assim, após biossíntese protéica, podemos encontrar no veneno proteinases maduras resultantes da biossíntese de precursores da classe P-la, formadas pelo domínio catalítico contendo a seqüência consenso estendida para a ligação do átomo de zinco com massa molecular entre $20 \mathrm{kDa}$ e $25 \mathrm{kDa}$ (BJARNASON e FOX, 1995; BARRETT et al., 1998). Em geral estas proteinases apresentam um número variado de cisteínas em suas seqüências, em torno de quatro a sete resíduos, formando de duas a três pontes de dissulfeto. Pertencem a esta classe as metaloproteinases atrolisina-C, HT-2, acutolisina-A, e BaP1, entre outras (FOX e SERRANO, 2005, 2008b). Esta classe é menos hemorrágica do que a classe P-III, sugerindo que domínios adicionais da classe P-III possam contribuir para o potencial hemorrágico.

Os precursores das enzimas da classe P-Il possuem, além do peptídeo sinal e do pró-domínio, o domínio disintegrina na porção carboxil do domínio catalítico. Estes precursores podem gerar proteínas maduras formadas somente pelo domínio catalítico ou somente o domínio tipo-disintegrina (P-lla), como a atrolisina-E, e também proteínas que conservam o domínio disintegrina na proteína madura como 
as metaloproteinases jerdonitina (monomérica da classe P-Ilb) e bilitoxina-1 (dimérica da classe P-Ilc). Estes precursores ainda podem gerar disintegrinas verdadeiras, que contêm a seqüência RGD em sua estrutura, encontradas como proteínas únicas nos venenos como a contortrostatina e a acostatina, disintegrinas homo- e heterodiméricas, das classes P-lld e P-lle, respectivamente (FOX e SERRANO, 2005, 2008b).

Já as proteinases da classe P-III são proteínas com massa molecular entre 50 kDa e 110 kDa que apresentam na sua forma madura, além do domínio catalítico, o domínio tipo disintegrina seguido de um domínio rico em resíduos de cisteínas na região C-terminal (BJARNASON e FOX, 1995). A esta classe pertencem proteinases formadas pelos domínios citados, na forma monomérica (P-IIla) como a atrolisina-A, HF3 e bothropasina e também na forma dimérica (P-IIIc), como a VAP1 (FOX e SERRANO, 2005, 2008b).

Ainda encontramos no veneno uma proteína madura composta somente pelos domínios tipo disintegrina e rico em cisteínas, formada pelo processamento proteolítico de precursores da classe P-IIlb, porém, o domínio catalítico destes precursores ainda não foi isolado do veneno (FOX e SERRANO, 2005, 2008b).

A antiga classe P-IV, hoje denominada classe P-IIId, é composta por enzimas que apresentam uma cadeia contendo os domínios encontrados nas proteinases da classe P-III, e mais duas cadeias de lectinas ligadas ao domínio rico em cisteínas por pontes dissulfeto. São representantes desta classe as proteinases RVV-X

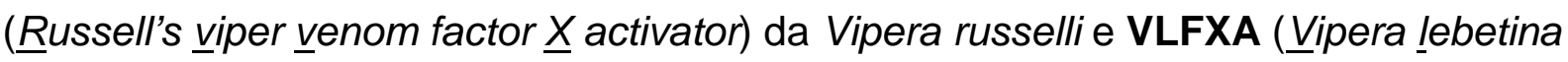
venom factor $\underline{X}$ activator) da Vipera lebetina, ambas com atividade de ativação do fator $X$ da coagulação (FOX e SERRANO, 2005, 2008b).

O pró-domínio das metaloproteinases possui seqüência altamente conservada, compreendendo cerca de 190 resíduos de aminoácidos. Apresenta uma seqüência consenso conservada, PKMㅡGVT, localizada cerca de 20 posições antes do resíduo N-terminal da proteína madura (BOTOS et al., 1995). Tanto o peptídeo sinal quanto o pró-domínio, estão presentes apenas nos precursores das proteinases.

É no domínio catalítico das metaloproteinases que encontramos a seqüência consenso estendida $\mathbf{H}-\mathbf{E}-\mathbf{X}-\mathbf{X}-\mathbf{H}-\mathbf{X}-\mathbf{X}-\mathbf{G}-\mathbf{X}-\mathbf{X}-\mathbf{H}$ onde ocorre a ligação do zinco, e também, a seqüência $\mathbf{C}-\mathbf{I}-\mathbf{M}$, conhecida como Met-turn. 
O domínio metaloproteinase das toxinas hemorrágicas de venenos atua primordialmente promovendo a degradação da membrana basal dos capilares sangüíneos, e do estroma local, permitindo o escape de sangue dos capilares (BARAMOVA et al., 1989), seja por extravasamento de sangue através de células endoteliais danificadas (hemorragia "per rhexis") (MOREIRA et al., 1992, 1994) ou através do alargamento das junções entre as células endoteliais, com conseqüente escape de sangue (hemorragia por "diapedese") (GONÇALVES e MARIANO, 2000; GUTIERREZ et al., 2005).

Essas enzimas também são capazes de digerir proteínas da cascata da coagulação sangüínea, tais como, fibrinogênio, fibrina, e fator von Willebrand (KAMIGUTI et al., 1994; HAMAKO et al., 1998; LAING e MOURA-DA-SILVA, 2005; SERRANO et al., 2007).

O domínio tipo disintegrina difere das disintegrinas verdadeiras, pois apresenta a seqüência E-C-D (Glu-Cys-Asp) na região onde se encontra a seqüência R-G-D (Arg-Gly-Asp) nas disintegrinas verdadeiras. Sua função não está completamente elucidada, entretanto, alguns trabalhos mostraram que este domínio pode ter um papel na atividade das metaloproteinases da classe P-III, como inibição da agregação plaquetária e modulação da atividade hemorrágica em conjunto com o domínio catalítico (JIA et al., 1997; YOU et al., 2003; TANJONI et al., 2003).

O domínio rico em cisteínas possui uma grande quantidade de resíduos de cisteína, que, estão interligados por pontes dissulfeto. Este domínio é observado em toxinas hemorrágicas e não hemorrágicas e sua função parece estar relacionada ao direcionamento dessas proteinases aos seus alvos celulares e plasmáticos (JIA et al., 2000; KAMIGUTI et al., 2003; SERRANO et al., 2005; SERRANO et al., 2006; SERRANO et al., 2007).

Recentemente, estudos cristalográficos de duas metaloproteinases da classe P-III, VAP1 isolada do veneno de Crotalus atrox, e VAP2B/catrocollastatina, isolada do mesmo veneno, mostraram que o domínio tipo disintegrina, subdivide-se em dois subdomínios, Ds (Disintegrin shoulder) e Da (Disintegrin arm), e é encoberto pelo domínio rico em cisteínas, ficando assim inacessível para a ligação a outras proteínas; já o domínio rico em cisteínas foi subdividido também em dois domínios, Cw (Cysteine wrist) e Ch (Cysteine hand), onde foi identificada uma região denominada hiper variável (HVR), à qual foi atribuída a capacidade de interagir com 
alguns ligantes das metaloproteinases, já que esta região está exposta na molécula e próxima ao domínio catalítico (TAKEDA et al., 2006; IGARASHI et al., 2007).

Proteínas nativas e recombinantes, compostas pelos domínios tipo disintegrina e rico em cisteínas de toxinas hemorrágicas de venenos, são potentes inibidores da agregação plaquetária por bloquearem a ligação do colágeno à integrina $\alpha 2 \beta 1$ das plaquetas (JIA et al., 1997; SHIMOKAWA et al., 1997; SOUZA et al., 2000; MOURA-DA-SILVA et al., 2001). Por essas razões, acredita-se que a hemorragia causada pelas metaloproteinases de venenos resulte do efeito sinérgico da degradação proteolítica de proteínas da membrana basal dos capilares sangüíneos, de proteínas plasmáticas, e da inibição da agregação plaquetária (FOX e LONG, 1998).

Seals e Courtneidge (2003) sugeriram que o domínio rico em cisteínas complementaria a capacidade de ligação do domínio tipo disintegrina e talvez conferisse especificidade às interações mediadas pelo domínio tipo disintegrina das ADAMs. O domínio rico em cisteínas da ADAM12 (e provavelmente o domínio tipo disintegrina) está envolvido na adesão celular dos fibroblastos e dos mioblastos (ZOLKIEWSKA, 1999). Também os domínios tipo disintegrina e rico em cisteínas da ADAM13 podem se ligar à fibronectina e à subunidade $\beta 1$ das integrinas, e esta ligação é inibida com anticorpos para o domínio rico em cisteínas e também para para a subunidade $\beta 1$ (GAULTIER, 2002).

Considerando-se a composição multidominial das metaloproteinases hemorrágicas da classe P-III, é possível que estas toxinas apresentem mais de um sítio de interação com as plaquetas promovendo a inibição da agregação. Foi inicialmente mostrado por Zhou et al. (1995) que a catrocollastatina, uma metalloproteinase da classe P-III do veneno de C. atrox, era capaz de inibir a agregação plaquetária e a adesão ao colágeno. Da mesma forma, a crovidisina, também da classe P-III, isolada do veneno de $C$. viridis, foi capaz de inibir a interação plaqueta-colágeno (LIU e HUANG, 1997). Paralelamente, o fato de outras metaloproteinases P-III, tais como a jararhagina e a kaouthiagina, serem capazes de clivar o vWF e assim causar a ruptura de sua estrutura, pode também contribuir para a geração da hemorragia (KAMIGUTI et al., 1996; HAMAKO et al., 1998; SERRANO et al., 2007).

Também o domínio rico em cisteínas recombinante da atrolisina- $A$, uma metaloproteinase da classe P-III do veneno de C. atrox, foi capaz de ligar-se ao 
colágeno tipo I e ao $v W F$, verificado por ensaios de ligação em fase sólida e por ensaios de ressonância plasmônica de superfície, no sistema BIAcore ${ }^{\mathrm{TM}}$. Ainda, esta proteína foi capaz de inibir a ligação do colágeno tipo I ao vWF (SERRANO et al., 2005).

A classe P-III contêm as enzimas mais hemorrágicas, e são capazes de degradar as proteínas da matriz extracelular (FOX e SERRANO, 2005). A ação proteolítica sobre proteínas da matriz extracelular in vitro é lenta em oposição ao que ocorre in vivo, onde o efeito hemorrágico do veneno ou das metaloproteinases isoladas ocorre imediatamente após a picada ou injeção experimental (LOMONTE et al., 1994).

Trabalhos recentes têm comparado a ação de metaloproteinases, tanto da classe P-I quanto da classe P-III, sobre substratos protéicos da matriz extracelular e sobre proteínas plasmáticas envolvidas na regulação da hemostasia, em ensaios in vitro e in vivo. Escalante et al. (2006), comparando os efeitos da BaP1, uma metaloproteinase da classe $\mathrm{P}-\mathrm{I}$ do veneno de $B$. asper, e da jararhagina, metaloproteinase da classe $\mathrm{P}$-III do veneno de $B$. jararaca, demonstraram que estas metaloproteinases têm atividade proteolítica similar sobre a azocaseína. Entretanto, sobre substratos protéicos da matriz extracelular, como a laminina e o nidogênio, a BaP1 apresentou proteólise limitada in vitro, já a jararhagina clivou preferencialmente o nidogênio. Em análises de imunohistoquímica das áreas hemorrágicas no músculo gastrocnêmio, verificou-se uma diminuição acentuada da laminina, do nidogênio e do colágeno tipo IV, e também do marcador de células endoteliais, o receptor VEGFR-2. Os autores sugeriram que a perda destas proteínas da membrana basal, provavelmente ocorreu em decorrência da combinação de proteólise limitada e da ação de forças biofísicas hemodinâmicas, que levaram à desestabilização da matriz extracelular (ESCALANTE et al., 2006).

Baldo et al. (2008) também comparando uma metaloproteinase da classe P-III (jararhagina) com uma metaloproteinase da classe $\mathrm{P}-\mathrm{I}$ (BnP1, isolada do veneno de B. neuwiedı), evidenciaram que embora a BnP1 não induza hemorragia como a jararhagina, ambas hidrolisam o fibrinogênio e a fibrina in vitro e induzem 0 desprendimento e a diminuição de células endoteliais viáveis em ensaios com HUVECs (células do cordão umbilical humano), sendo a apoptose um dos prováveis mecanismos envolvidos na morte de células endoteliais. 
Estevão-Costa et al. (2000) demonstraram que as metaloproteinases mutalisina I e mutalisina II, das classes P-III e P-I respectivamente, isoladas do veneno de Lachesis muta muta, hidrolisaram o fibrinogênio e a fibrina in vitro, com diferentes padrões de hidrólise.

Bello et al. (2006), após isolarem e caracterizarem uma metaloproteinase da classe P-I, a leucurolisina-a, do veneno de B. leucurus, demonstraram que esta hidrolisava a fibrina, o fibrinogênio e a fibronectina, mas não a laminina. Por outro lado, LHF-II, uma metaloproteinase da classe P-I do veneno de L. muta muta, foi capaz de hidrolisar laminina, fibronectina e colágeno tipo IV (RUCAVADO et al., 1999), indicando que há variação de especificidade de substrato macromolecular entre as metaloproteinases da classe P-I.

Em trabalho recente foi isolada uma metaloproteinase da classe $\mathrm{P}-\mathrm{I}$ do veneno de $B$. jararaca, bothrojaractivase, com massa molecular em torno de $22 \mathrm{kDa}$ e que gera trombina a partir da ativação de protrombina (BERGER et al., 2008). Já a BjussuMP-II, uma metaloproteinase da classe $\mathrm{P}-\mathrm{I}$ isolada do veneno de $B$. jararacussu, não induz hemorragia local, miotoxicidade e nem letalidade, porém apresenta atividade proteolítica sobre o fibrinogênio, fibrina , gelatina, colágeno I e caseína de forma dose-dependente, e inibe a agregação plaquetária (MARCUSSI et al., 2007).

\subsection{Importância das cadeias de carboidratos na atividade e na estrutura das protéinas}

Nos eucariotos, a maioria das proteínas secretadas e associadas a membranas são glicosiladas. Proteínas glicosiladas podem ser formadas por uma ampla variedade de carboidratos unidos em estrutura linear ou ramificados. Após a síntese da cadeia polipeptídica, os carboidratos podem ser ligados a determinados aminoácidos de três formas: 1) ao nitrogênio da cadeia lateral do resíduo de asparagina pertencente à tríade Asn-X-Ser/Thr (sendo $\mathrm{X}$ diferente de prolina e ácido aspártico) ( $N$-glicosilações); 2) ao grupo hidroxila de resíduos de aminoácidos hidroxilados como a serina, tirosina ou treonina (O-glicosilações); 3) ou ainda podemos encontrar cadeias de açúcares ligadas a proteínas com âncora 
glicosilfosfatidilinositol - GPI (DWEK et al., 1993; OPDENAKKER, et al., 1993; WYSS e WAGNER, 1996).

O papel funcional das cadeias glicosídicas ligadas a seqüências polipeptídicas não está completamente elucidado, no entanto muitos autores reportam a estas cadeias atividades importantes como: influência na estrutura terciária protéica através de interações entre os açúcares e a proteína; alteração da polaridade e solubilidade da proteína, visto que os agregados de carboidratos são altamente hidrofílicos; também, a densidade e a carga negativa das cadeias de carboidratos carregados negativamente podem proteger algumas proteínas da ação de enzimas proteolíticas. Ainda, os carboidratos podem ter um papel na manutenção da conformação estrutural da proteína, no reconhecimento molecular entre célula/célula e célula/proteína, e também na transdução de sinais após ligação com receptor (VARKI, 1993; OPDENAKKER, et al., 1993; WYSS e WAGNER, 1996).

Trabalhos envolvendo o estudo do papel das porções glicosídicas nas atividades desenvolvidas por algumas proteinases como a RVV-X, uma metaloproteinase que tem atividade de ativação do fator $X$ da coagulação, teve sua atividade afetada após a remoção das cadeias de carboidratos por $N$-deglicosilação, assim como alterações significantes em sua estrutura (GOWDA et al., 1996). Tanto a jararhagina quanto a $\mathrm{ACLH}$, uma metaloproteinase do veneno de Agkistrodon contortrix laticinctus, não induziram hemorragia na derme de camundongo após serem $N$-deglicosiladas (GARCIA, et al., 2004). Escrevente et al. (2008) demonstraram que a ADAM10, uma metaloproteinase de mamífero com atividade sheddase, após ser $N$-deglicosilada teve sua atividade enzimática afetada e ainda tornou-se suscetível à degradação proteolítica. A Bothrops protease A (BPA), é uma serinoproteinase extremamente glicosilada do veneno da $B$. jararaca que apresenta atividade proteolítica específica sobre o fibrinogênio, e cuja $N$-deglicosilação de parte de suas cadeias de carboidratos levou à potencialização de sua atividade proteolítica, sugerindo que a remoção de parte destas cadeias de carboidratos possa ter facilitado a interação da BPA com o fibrinogênio (PAES LEME et al., 2008). 


\subsection{Proteínas plasmáticas}

Os vasos capilares são particularmente susceptíveis aos efeitos dos venenos de serpentes, que causam alteração na permeabilidade vascular, extravasamento de plasma e hemácias, ruptura da junção intracelular e lise de células endoteliais (BJARNASON e FOX, 1995). Pacientes monitorados após envenenamento por $B$. jararaca apresentaram hipoagregação plaquetária induzida por ADP e colágeno, além de níveis anormais de degradação do fibrinogênio e da fibrina (SANOMARTINS, et al., 1997). Ainda, segundo Gutierrez et al. (2005), forças biofísicas associadas ao fluxo sangüíneo teriam em conjunto com a degradação de componentes da matriz extracelular, e a conseqüente perturbação da interação entre estes componentes e as células endoteliais, um importante papel na geração da hemorragia in vivo.

A formação do coágulo de fibrina no sítio de lesão endotelial constitui processo crucial para a manutenção da integridade vascular. Os mecanismos envolvidos nesse processo são dependentes da integridade anatômica e funcional do sistema hemostático e devem ser rigorosamente regulados de modo à simultaneamente contrapor-se à perda excessiva de sangue e evitar a formação de trombos intravasculares decorrentes de formação excessiva de fibrina.

A conversão do fibrinogênio em fibrina é uma das reações bioquímicas mais importantes na formação e estabilização do coágulo sangüíneo, sendo parte fundamental na regulação do sistema hemostático. A fibrina é formada após a trombina clivar as cadeias $A \alpha$ e $B \beta$ do fibrinogênio formando dois fibrinopeptídeos $A$ (FPA) e dois fibrinopeptídeos $B$ (FPB), dando início à polimerização da fibrina (SCHERAGA e LASKOWSKI, 1957; SCHERAGA, 2004).

O fibrinogênio é uma glicoproteína plasmática hexamérica, composta por duplas de três cadeias polipeptídicas denominadas $A \alpha, B \beta$ e $Y$ de massas moleculares de 66.500 Da, 56.000 Da e 47.000 Da, respectivamente, e unidas por pontes dissulfeto (figura 4) (MCKEE et al., 1966). 


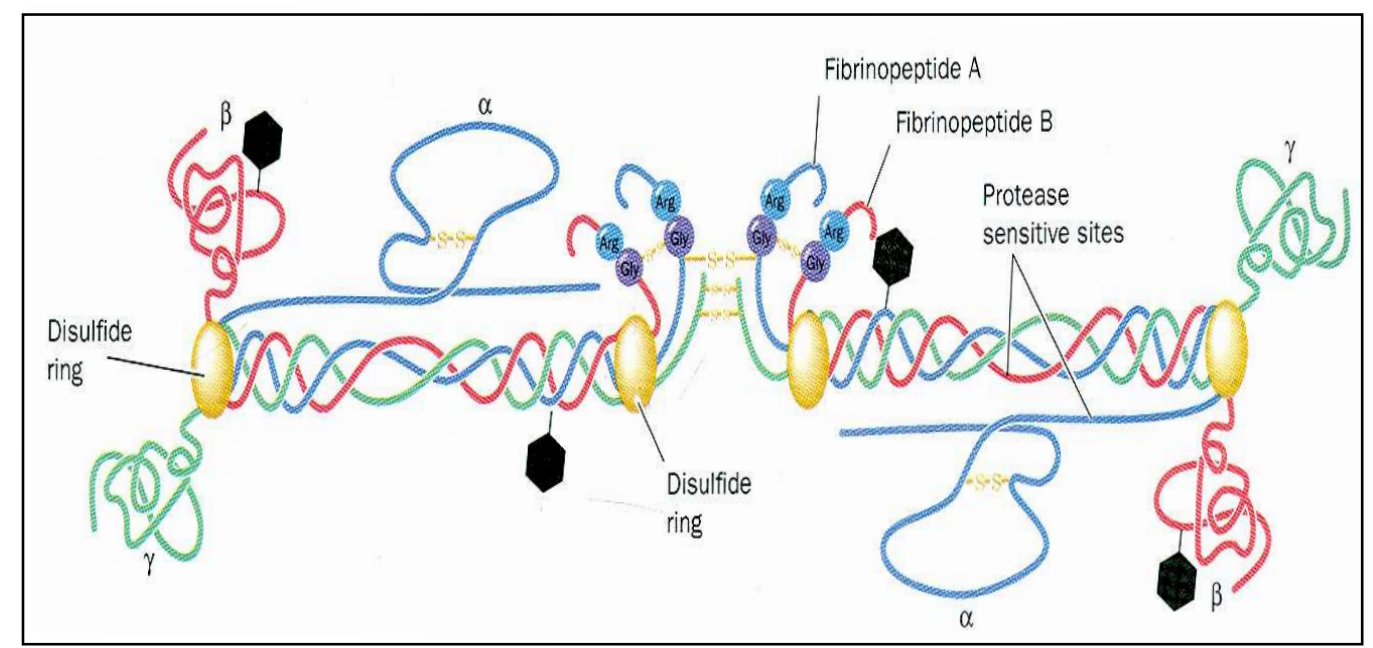

Figura 4. Características estruturais da molécula de fibrinogênio. Representado em azul cadeia $\alpha$, em vermelho cadeia $\beta$ e em verde cadeia $y$.

FONTE: http://www.biochemistry-imm.org/.

A vitronectina, também conhecida como proteína-S, ou "serum spreading factor" ou epibolina, é uma glicoproteína adesiva, presente no plasma humano na concentração de aproximadamente $4 \mu \mathrm{M}$, mas também pode ser encontrada no líquido amniótico, urina, plaquetas e matriz extracelular (HAYMAN et al., 1983; TOLLEFSEN et al., 1990). É encontrada na forma circulante como uma mistura de duas formas, uma apresentando uma cadeia de $75 \mathrm{kDa}$, e outra forma truncada que é clivada após a $\mathrm{Arg}^{379}$ por uma protease endógena, formando duas cadeias de 65 $\mathrm{kDa}$ e $10 \mathrm{kDa}$ ligadas por pontes dissulfeto (figura 5) (HAYMAN et al., 1983; TOLLEFSEN et al., 1990).

A vitronectina está envolvida na regulação da fibrinólise através de interações com o inibidor-1 do ativador do plasminogênio derivado de plaquetas (PREISSNER et al., 1989); atua também na modulação da cascata do complemento, impedindo a formação do complexo de ataque à membrana associando-se ao complexo C5b-9 (DAHLBICK e PODACK, 1985; BHAKDI et al., 1988) e liga-se a receptores específicos de membrana dos fibroblastos e de células endoteliais mediando a ligação e o spreading destas células (SUZUKI et al., 1985). 


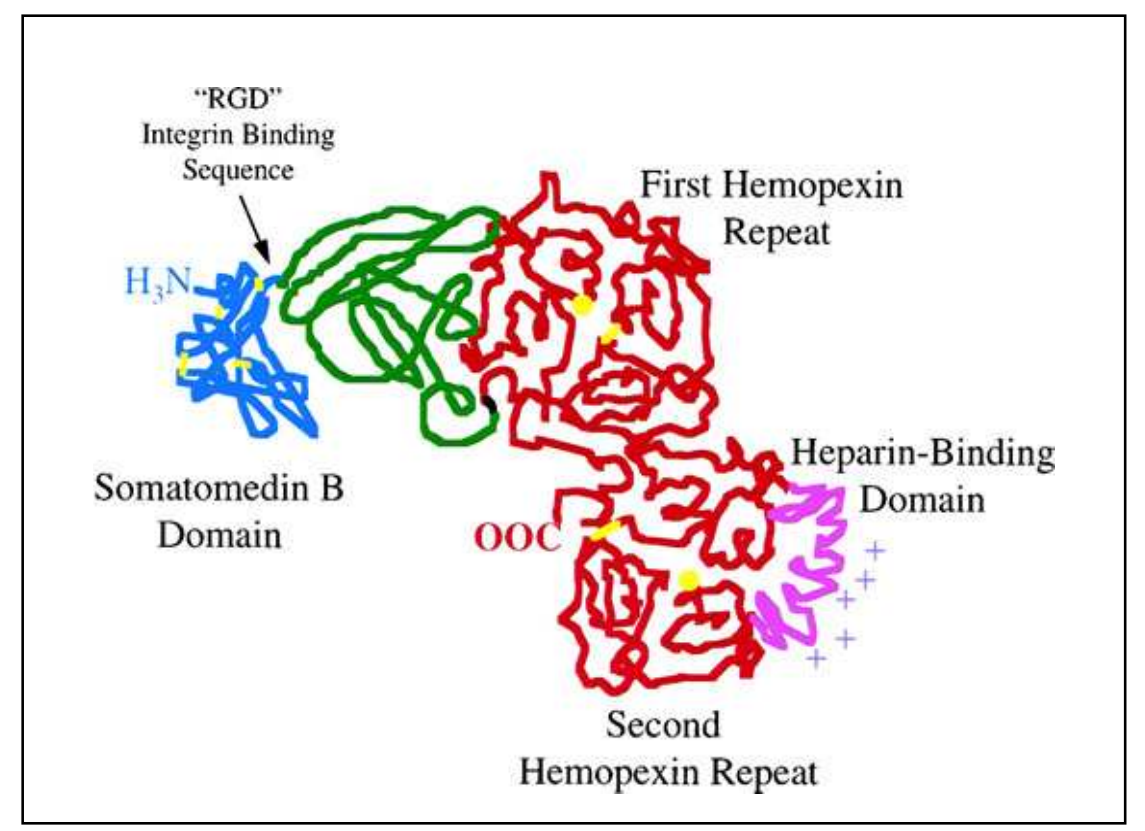

Figura 5. Modelo da estrutura da vitronectina. O domínio Somatomedina B está representado em azul, seguido da seqüência RGD; em verde o domínio de ligação ao colágeno e em vermelho os dois domínios homólogos à hemopexina interrompidos por um sitio de ligação à heparina (em rosa).

FONTE: Gibson et al. (1999).

Outra proteína que pode ser encontrada tanto no plasma como depositada em tecidos, inclusive como constituinte da membrana basal é a fibronectina (MATSUDA, 1982), uma glicoproteína adesiva composta por duas cadeias polipeptídicas similares de 250 e $280 \mathrm{kDa}$ ligadas por duas pontes dissulfeto na região C-terminal. Cada cadeia é formada por seqüências repetidas de aminoácidos chamadas de módulos (doze módulos do tipo I - Fn1, dois do tipo II - Fn2 e quinze do tipo III Fn3) (PETERSEN et al., 1983). Estes módulos são organizados em domínios funcionais que se ligam a integrinas, colágeno, heparina, fibrina e ao fator XIII. Um esquema da estrutura da fibronectina é mostrado na figura 6.

Vários tipos celulares são capazes de sintetizar fibronectina como as células parenquimatosas hepáticas, praticamente todas as células sinusoidais, células de Kupffer, células endoteliais e estelares (VOSS et al., 1979).

Existem cerca de 20 isoformas de fibronectina processadas por splicing alternativo de um mesmo gene, que ocorre principalmente na região III (figura 6). A região EDA da fibronectina, um dos segmentos onde ocorre splicing, é altamente 
expressa durante processos biológicos envolvendo migração e proliferação celular como no desenvolvimento embrionário, transformações celulares malignas e nas cicatrizações de feridas (MANABE et al., 1997).

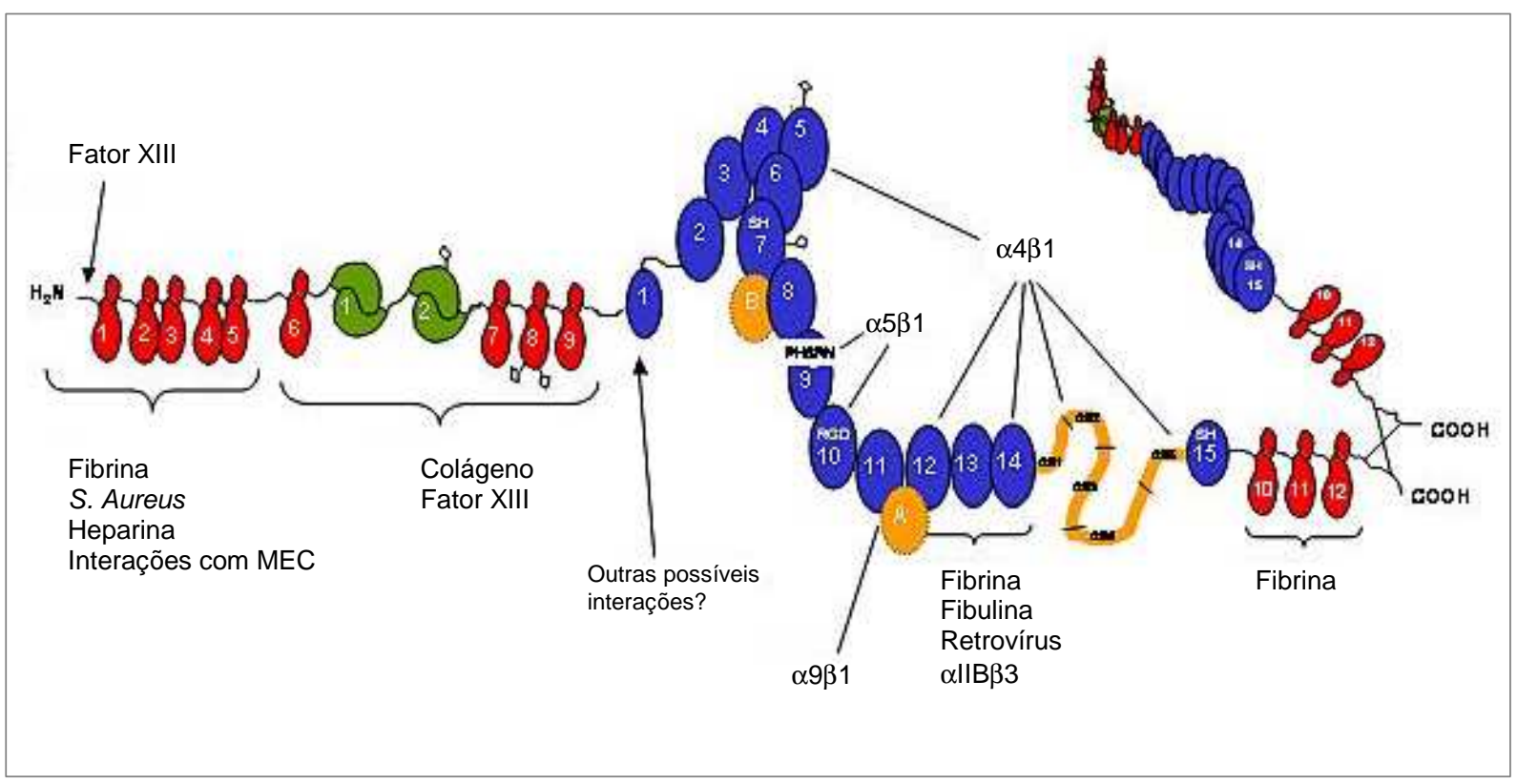

Figura 6. Estrutura esquemática da fibronectina. Em vermelho estão representados os módulos tipo I (Fn1), em verde os módulos tipo II (Fn2), em azul os módulos tipo III (Fn3) e em laranja as regiões onde ocorrem splicing alternativo no mRNA.

FONTE: Adaptado do site http://home.comcast.net/ kennethingham/newsite/index.htm.

A fibronectina tem importante papel na hemostasia, onde se liga à fibrina, aumentando a ativação plaquetária e gerando uma matriz provisória responsável pela adesão celular e migração durante a cicatrização de feridas. Ainda, a fibronectina liga-se a sítios expostos na fibrina que não são acessíveis no fibrinogênio (MAKOGONENKO, 2002). Está envolvida ainda em processos de adesão celular, promove migração celular durante o desenvolvimento embrionário, cicatrização de feridas, e na progressão tumoral (HYNES, 1990). 


\subsection{Proteínas da matriz extracelular}

A matriz extracelular (MEC) dá suporte estrutural às células nos tecidos e é de fato o que define o tecido conjuntivo. Inclui a matriz intersticial, presente entre as células, e a membrana basal, constituída de camadas de matriz extracelular nas quais se apóiam as células epiteliais. A MEC é formada por uma variedade de macromoléculas representadas principalmente por colágenos fibrilares, fibras elásticas, glicoproteínas estruturais e proteoglicanos, além de vários tipos celulares imersos nesta matriz (SUKI e BATES, 2008). As interações entre células e a MEC influenciam a regulação fisiológica dos tecidos, a remodelação e a reorganização da MEC (BREEN, 2000). A matriz extracelular tem um importante papel na sustentação do endotélio vascular, por meio de interações adesivas com integrinas presentes na superfície das células endoteliais, regulando a proliferação, a migração, a morfogênese e a estabilização dos vasos sangüíneos, etapas importantes em processos de neovascularização (DAVIS e SENGER, 2005).

Um dos componentes mais abundantes da MEC é o colágeno I. Sua estrutura é composta por três cadeias $\alpha$, caracterizadas por seqüências repetidas de Gly-X-Y, onde $X$ representa os resíduos de prolina e $Y$ os resíduos de hidroxiprolina, que formam os domínios colagenosos, e ainda possui dois domínios não colagenosos nas regiões $\mathrm{N}$ e C-terminais (BROWN e TIMPL, 1995). O colágeno I é um heterotrímero, formado por duas cadeias a1(I) idênticas e uma cadeia a2(I) que se unem em uma conformação estrutural em a-hélice característica dos colágenos (figura 7A). É o principal constituinte dos tendões, pele, ligamentos, córnea e de muitos tecidos conectivos e está envolvido não somente na manutenção estrutural, desenvolvimento e reparo de tecidos (GELSE et al., 2003), como também na adesão e agregação plaquetária induzida por colágeno através dos receptores da glicoproteína VI (GPVI) e a2ß1 (SARRATT et al., 2004, 2005).

O colágeno VI, outro colágeno com ampla distribuição nos tecidos conectivos, está ancorado em largas estruturas tais como nervos, vasos sangüíneos e colágenos fibrilares. Está envolvido na migração e diferenciação celular e tem um importante papel na interação célula-matriz extracelular (RICARD-BLUM et al., 2000). É uma glicoproteína heterotrimérica formada por três cadeias geneticamente distintas $\alpha 1(\mathrm{VI}), \alpha 2(\mathrm{VI})$, e $\alpha 3(\mathrm{VI})$ (JANDER et al., 1983). Todas as cadeias são 
formadas por uma pequena região colagenosa e por domínios globulares nas regiões $\mathrm{N}$ e C-terminais que tem homologia com o domínio $\mathrm{A}$ do $V W F(V W F A)$ e que variam em número em todas as cadeias (figura 7B) ( $\mathrm{CHU}$ et al., 1990). Uma importante função do colágeno $\mathrm{VI}$, localizado no subendotélio, é a ligação ao $v W F$, promovendo a adesão plaquetária no sitio de injuria vascular (RAND et al., 1993). Segundo Mazzucato et al. (1998) a interação entre sítios na cadeia $\alpha 3$ do colágeno $\mathrm{VI}$ e os domínios $\mathrm{A} 1$ e $\mathrm{A} 3$ do $v W F$ é um possível mecanismo na mediação da adesão plaquetária.

A
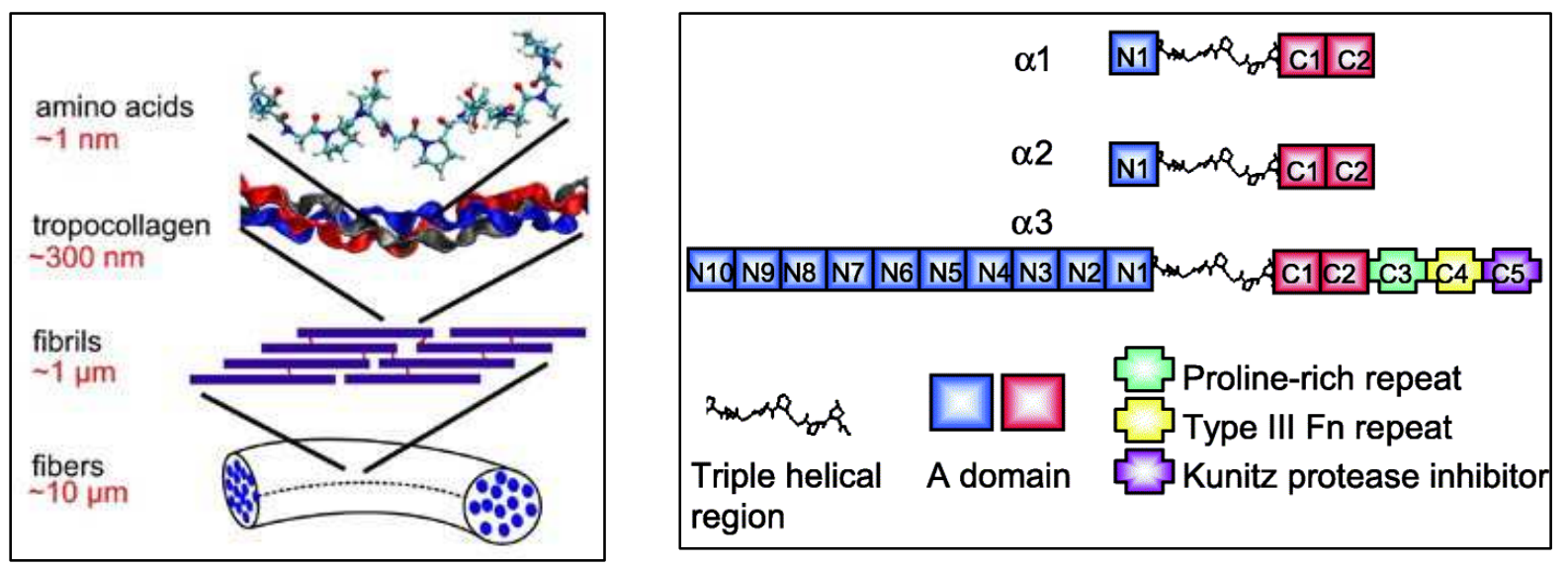

Figura 7. Esquema das estruturas do Colágeno I e VI. (A) Esquema da organização das cadeias do colágeno I até a formação de fibras colagenosas. (B) Organização dos domínios das cadeias a1, a2 e a3 do colágeno VI. Os retângulos azuis e vermelhos representam os domínios $\checkmark W F A$ das regiões $\mathrm{N}$ e C-terminais, respectivamente; em verde região rica em prolina; em amarelo domínios com repetições de fibronectina tipo III e o retângulo roxo domínio inibidor de protease Kunitz. A região colagenosa é representada em preto.

FONTE: (A):http://web.mit.edu/newsoffice/2006/collagen.html; (B): Baldock et al. (2003).

A membrana basal é uma estrutura especializada da matriz extracelular que envolve a maioria dos tecidos. Além do colágeno tipo IV e da laminina, que são os componentes majoritários, a membrana basal da maioria dos animais adultos é também formada pelos colágenos XV e XVIII, pelo perlecano (um proteoglicano) e entactina/nidogênio, uma proteína multiadesiva pequena que interage com a maioria dos compontes da matriz (figura 8) (AUMAILLEY e KRIEG, 1996; TIMPL, 1996; FOX et al., 1991). 
A laminina, um dos maiores componentes da membrana basal, é uma glicoproteína com mais de 12 isoformas clonadas e seqüenciadas, formadas pela combinação de três cadeias polipeptídicas diferentes: 5 cadeias $\alpha$ ( $\alpha 1$ - $\alpha 5), 3 \beta$ ( $\beta 1$ ß3) e 3 y ( $\gamma 1$ - $ү 3$ ) (MINER e YURCHENCO, 2004). A laminina-1 ( $\alpha 1 \beta 1 \gamma 1)$ isolada do tumor EHS, foi a primeira laminina identificada (TIMPL et al., 1979), formada pelas

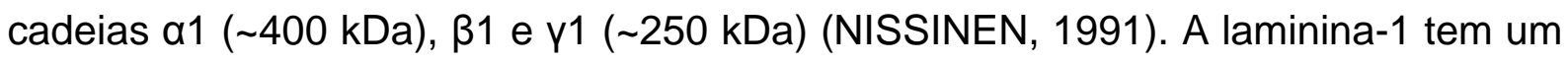
importante papel durante a diferenciação celular e está envolvida em diferentes funções como adesão, migração, proliferação, apoptose e expressão genes (AUMAILLEY e SMYTH, 1998).

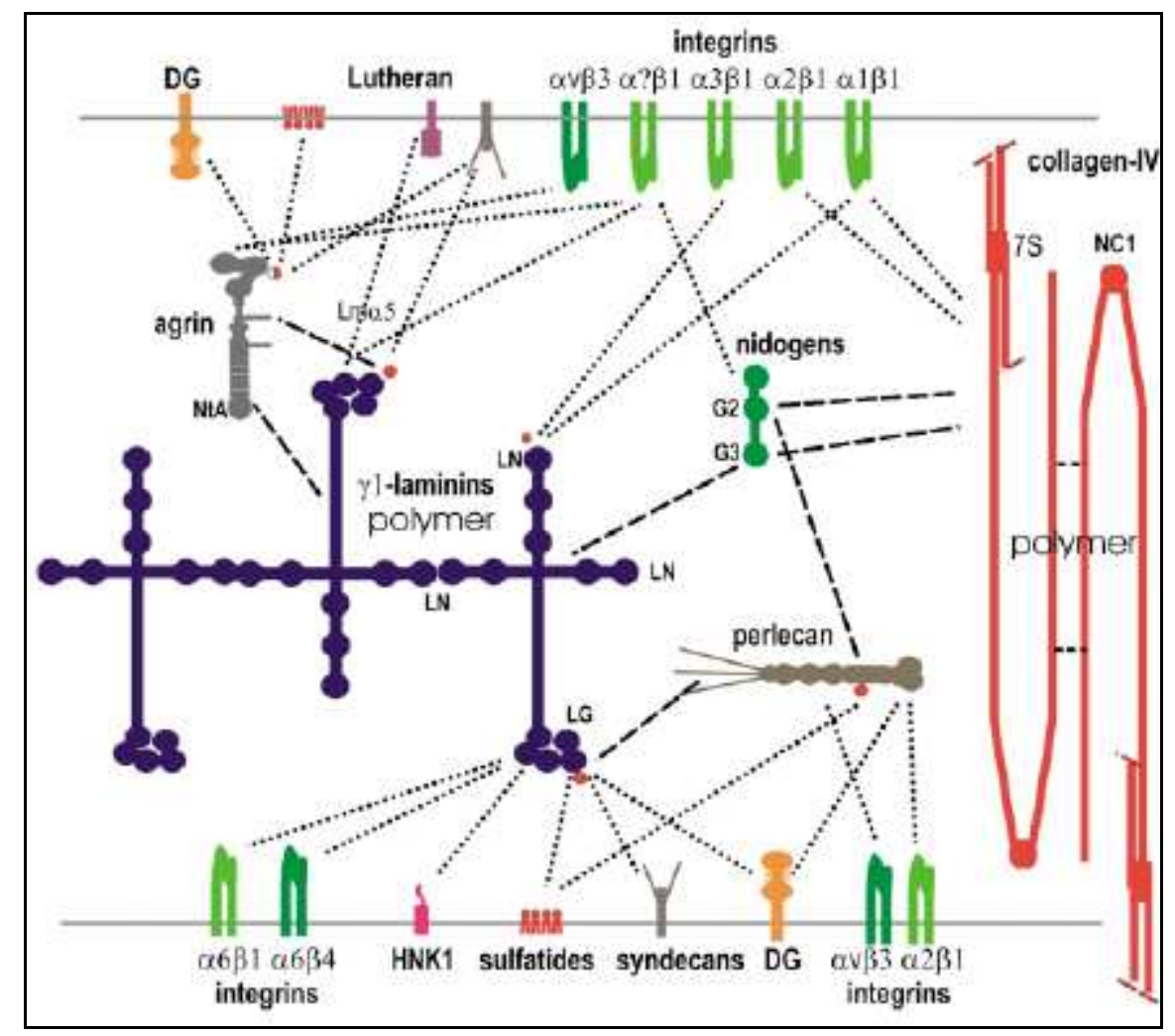

Figura 8. Representação esquemática da membrana basal. Interações entre os componentes da membrana basal: em azul a molécula de laminina, em vermelho o colágeno IV e em verde com seus três domínios globulares o nidogênio interligando moléculas da lamina basal.

FONTE: Yurchenco et al. (2004).

O componente estrutural mais abundante da membrana basal é o colágeno IV. Seis cadeias geneticamente diferentes já foram clonadas e seqüenciadas 
(BROWN e TIMPL, 1995), porém a composição contendo as cadeias [ $\left.\alpha_{1}(\mathrm{IV})\right] 2 \alpha_{2}(\mathrm{IV})$ é a que tem maior distribuição na membrana basal dos tecidos, como na membrana basal glomerular, na matriz mesenquimal e nas membranas de túbulos e vasos (HUDSON et al., 1993). A molécula do colágeno IV é formada por uma tripla hélice de $400 \mathrm{~nm}$ de comprimento com seqüências repetidas de Gly-X-Y interrompidas cerca de 20 vezes por segmentos não-helicoidais que conferem flexibilidade à molécula. Ainda, as moléculas do colágeno IV associam-se através destes mesmos segmentos não-helicoidais por interações laterais e também através dos grandes e pequenos domínios globulares nas regiões C- e N-terminais, respectivamente (YURCHENCO e RUBEN, 1988).

O nidogênio-1, ou entactina, é uma proteína de $150 \mathrm{kDa}$ aproximadamente, presente na membrana basal, com três domínios globulares (G1, G2 e G3), conectados por segmentos em forma de haste (FOX et al., 1991). Kimura et al. (1998) isolaram um novo membro da família do nidogênio, com massa molecular de $200 \mathrm{kDa}$, cuja seqüência apresenta $46 \%$ de identidade ao nidogênio-1 e domínios estruturais similares, denominado nidogênio-2.

\subsection{Proteínas isoladas do veneno de Bothrops jararaca}

O grande número de trabalhos sobre as ações in vivo e in vitro das metaloproteinases de venenos de serpentes, alguns dos quais foram descritos aqui, mostram que em muitos casos há uma interação específica de cada proteinase com um substrato protéico, seja este proteínas relacionadas com a hemostasia ou proteínas da matriz extracelular, e que, estas interações estão relacionadas com o quadro hemorrágico desenvolvido durante o envenenamento. $O$ que ainda não está claro é como estas proteinases interagem com cada substrato e de que forma a proteólise está relacionada com a hemorragia local observada principalmente com a metaloproteinases da classe P-III.

Para melhor entender o mecanismo de interação de proteinases de venenos de serpentes com seus substratos, analisamos comparativamente a interação de proteinases das classes P-I e P-III com algumas proteínas plasmáticas e da matriz extracelular, assim como a participação dos domínios não catalíticos das 
proteinases da classe P-III na interação com essas proteínas. Ainda, avaliamos a participação das porções glicosídicas destas proteinases na interação com estes substratos.

Para tanto isolamos do veneno de $B$. jararaca, duas metaloproteinases da classe P-III, HF3 e bothropasina, uma da classe P-I que será caracterizada neste trabalho e também a proteína DC, formada pelos domínios tipo disintegrina e rico em cisteínas.

O fator hemorrágico, HF3, é uma glicoproteína ácida, com pl de 3,9, de alta massa molecular (ASSAKURA et al., 1986). Sua atividade enzimática é dependente da manutenção das suas pontes dissulfeto e da presença do átomo de zinco em seu sítio ativo. Com dose mínima hemorrágica (DMH) de 15 ng, que corresponde à dose mínima necessária para causar uma área hemorrágica de $1 \mathrm{~cm}^{2}$ na derme de coelho, é a metaloproteinase hemorrágica mais potente do veneno da $B$. jararaca, encontrada em pequena quantidade no veneno, e é uma proteína relativamente estável, pois não sofre autólise (ASSAKURA et al., 1986). A determinação da especificidade hidrolítica do HF3 sobre a cadeia B da insulina, mostrou que a enzima tem preferência pela hidrólise de ligações peptídicas contendo Leu ou Phe na posição $P_{1}^{\prime}$ (ASSAKURA et al., 1986).

Silva et al. (2004) determinaram a seqüência completa de aminoácidos do HF3 pela clonagem molecular do cDNA, e demonstraram que o HF3 nativo e uma proteína recombinante composta pelos domínios tipo disintegrina e rico em cisteínas do HF3 (recDC-HF3), eram capazes de inibir a agregação plaquetária induzida por colágeno. Ainda, estes autores mostraram que o HF3 nativo, o HF3 inativado com ortofenantrolina e a proteína recDC-HF3 eram capazes de aumentar a atividade de fagocitose em macrófagos, mediada pela integrina $\alpha_{M} \beta_{2}$. Recentemente, Menezes et al. (2008), demonstraram que um peptídeo sintético, correspondendo à região hiper variável (HVR) do domínio rico em cisteínas do HF3, aumenta o rolamento de leucócitos intravascular e que esta atividade é inibida na presença de anticorpos anti- $\alpha_{M}$ e anti- $\beta_{2}$.

A bothropasina é uma metaloproteinase da classe P-III isolada do veneno de B. jararaca, com massa molecular em torno de $48 \mathrm{kDa}$ e que tem dose mínima hemorrágica de $1 \mu \mathrm{g}$ na derme de coelho (MANDELBAUM et al., 1982). É uma glicoproteína ácida (pl 4,8) que possui atividade proteolítica sobre a caseína e hidrolisa, preferencialmente, as ligações peptídicas His-Leu, Ala-Leu, Tyr-Leu e Phe- 
Phe da cadeia B da insulina (MANDELBAUM et al., 1982). A bothropasina apresenta alto grau de identidade (95,5\%) com a jararhagina (PAINE et al., 1992), uma proteína homóloga isolada do mesmo veneno e extensivamente caracterizada.

Recentemente foi determinada a estrutura cristalográfica da bothropasina, determinando o sítio para ligação do átomo de $\mathrm{Zn}^{2+}$ no domínio catalítico e três sítios para ligação de $\mathrm{Ca}^{2+}$, um no domínio catalítico e dois no domínio tipo disintegrina (figura 9). O domínio catalítico apresenta sete resíduos de cisteínas dos quais seis participam da formação de três pontes dissulfeto e um resíduo está livre e se localiza em uma região hidrofóbica e, portanto indisponível para formação de ponte dissulfeto; o domínio tipo disintegrina apresenta sete pontes dissulfeto enquanto que, o domínio rico em cisteínas apresenta seis pontes, sendo que estes dois domínios são interligados por uma ponte dissulfeto adicional (MUNIZ et al., 2008).

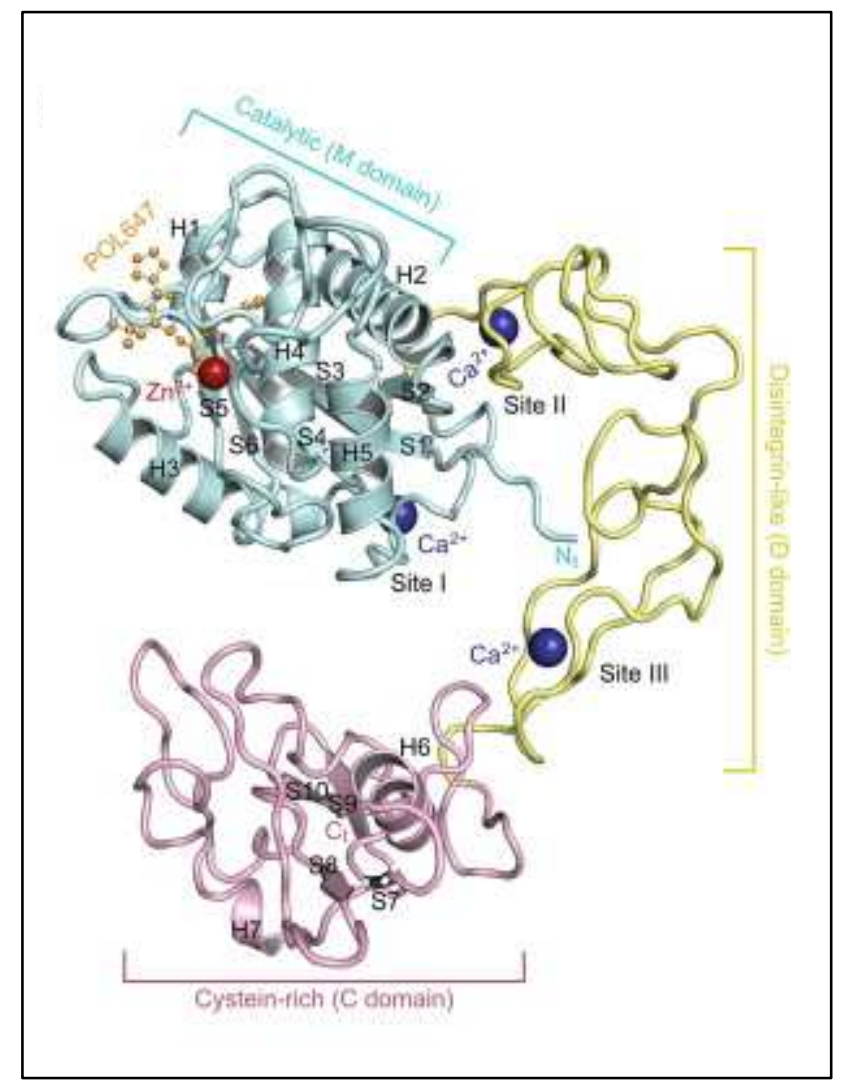

Figura 9. Estrutura cristalográfica da bothropasina. A figura apresenta os três domínios: catalítico (verde), tipo disintegrina (amarelo) e rico em cisteinas (lilás). A esfera vermelha representa o átomo de zinco e as esferas azuis os sitios para ligação dos átomos de cálcio.

FONTE: Muniz et al., (2008). 
Diferentemente das estruturas cristalográficas da VAP1 e da VAP2, onde a região ECD, no domínio tipo disintegrina, não fica exposta na molécula, na bothropasina o glutumato desta seqüência é acessível para possíveis interações (MUNIZ et al., 2008). Os autores sugerem ainda que a região hiper variável (HVR), determinada nas estruturas da VAP1 e VAP2, é altamente conservada na bothropasina, quando alinhada com as seqüências de outras proteínas da classe $P$ III como a acurhagyna e a acutolysina, propondo que as metaloproteinases da classe P-III sejam separadas em dois subgrupos: P-III-HVR e P-III HCR (hiper conservada).

Uma proteína composta pelos domínios tipo disintegrina e rico em cisteínas das metaloproteinases da classe $\mathrm{P}$-III foi isolada pela primeira vez do veneno de $B$. jararaca, e chamada de jararhagina-C por Usami et al. (1994). Esta proteína é gerada pela autólise de proteinases como a jararhagina (MOURA-DA-SILVA et al., 2003), a bothropasina (ASSAKURA et al., 2003) e a catrocollastatina (SHIMOKAWA et al., 1997). Tanto a jararhagina $C$, como a catrocollastatina $C$, inibem a agregação plaquetária induzida pelo colágeno (SHIMOKAWA et al., 1997). 


\section{ALGUMAS CONCLUSÕES}

Sugerimos que a BJ-PI seja uma metaloproteinase cujo precursor pertence à classe P-lla, denominado bothrostatina, e a proteinase isolada seja resultante do processamento proteolítico do mesmo. A BJ-PI é uma proteinase glicosilada, ainda que o cDNA que codifique a bothrostatina não apresente sítios putativos de glicosilação, não hemorrágica, com massa molecular de $22 \mathrm{kDa}$, com alta atividade específica sobre a caseína e foi identificada por análises de espectrometria de massas.

O HF3, a bothropasina e a proteína DC foram isolados do veneno $B$. jararaca em etapas que incluíram a saturação com sulfato de amônio entre $30 \%$ e $60 \%$, seguida de cromatografias de troca aniônica e de filtração em gel.

A bothropasina e a BJ-PI têm alta atividade proteolítica específica sobre o fibrinogênio e sobre a caseína, respectivamente, enquanto o HF3 tem baixa atividade sobre estas proteínas. Por outro lado o HF3 induz hemorragia com dose cerca de 40 vezes menor que a bothropasina.

A bothropasina apresenta apenas um sítio putativo de $\mathrm{N}$-glicosilação enquanto que o HF3 apresenta cinco destes sítios. As cadeias de carboidratos presentes nas moléculas das metaloproteinases são importantes na manutenção de suas atividades fibrinogenolítica, hemorrágica e também no reconhecimento e interação com os colágenos I e VI, seja por garantir estabilidade à estrutura protéica ou por participar da interação com os seus alvos protéicos.

Os ensaios de hidrólise in vitro mostraram que as proteínas plasmáticas e da matriz extracelular analisadas, com exceção do colágeno I, foram clivadas pelas metaloproteinases HF3, bothropasina e BJ-PI, porém, aparentemente com potências e especificidades diferentes.

Do conjunto de ensaios de ligação em fase sólida concluímos que as interações das metaloproteinases da classe P-III com seus ligantes, não são determinadas somente pelos domínios catalíticos, tipo disintegrina e rico em cisteínas, mas também pela presença de cadeias de carboidratos em suas estruturas, dependendo da proteinase e do ligante. 


\section{REFERÊNCIAS*}

ALFANDARI, D.; COUSIN, H.; GAULTIER, A.; SMITH, K.; WHITE, J. M.; DARRIBERE, T.; DESIMONE. D. W. Xenopus ADAM 13 is a metalloproteinase required for cranial neural crest-cell migration. Curr. Biol., v. 11, p. 918-930, 2001.

ANDREWS, R. K.; BERNDT, M. Snake venom modulators of platelet adhesion receptors and their ligands. Toxicon, v. 38, p. 775-791, 2000.

ASSAKURA, M. T.; REICHL, A. P.; MANDELBAUM, F. R. Comparison of immunological, biochemical and biophysical properties of three hemorrhagic factors isolated from the venom of Bothrops jararaca (jararaca). Toxicon, v. 24, p. 943-946, 1986.

ASSAKURA, M. T.; SILVA, C. A.; MENTELE, R.; CAMARGO, A. C.; SERRANO, S. M. Molecular cloning and expression of structural domains of bothropasin, a P-III metalloproteinase from the venom of Bothrops jararaca. Toxicon, v. 41, p. 217-227, 2003.

AUMAILLEY, M.; KRIEG, T. Laminins: a family of diverse multifunctional molecules of basement membranes. J. Invest. Dermatol., v. 106, p. 209-214, 1996.

AUMAILLEY, M.; SMYTH, N. The role of laminins in basement membrane function. J. Anat., v. 193, p. 1-21, 1998.

BALDO, C.; TANJONI, I.; LEÓN, I. R.; BATISTA, I. F.; DELLA-CASA, M. S.; CLISSA, P. B.; WEINLICH, R.; LOPES-FERREIRA, M.; LEBRUN, I.; AMARANTE-MENDES, G. P.; RODRIGUES, V. M.; PERALES, J.; VALENTE, R. H.; MOURA-DA-SILVA, A. $\mathrm{M}$. BnP1, a novel P-I metalloproteinase from Bothrops neuwiedi venom: biological effects benchmarking relatively to jararhagin, a P-III SVMP._Toxicon, v. 51, p. 54-65, 2008.

*De acordo com:

ASSOCIAÇÃO BRASILEIRA DE NORMAS TÉCNICAS. NBR 6023:

Informação e documentação: referencias: elaboração. Rio de Janeiro, 2002 
BARAMOVA, E. N.; SHANNON, J. D.; BJARNASON, J. B.; FOX, J. W. Degradation of extracellular matrix proteins by hemorrhagic metalloproteinases. Arch. Biochem. Biophys., v. 275, p. 63-71, 1989.

BARRETT, A. J.; RAWLINGS, N. D.; WOESSNER, J. F. Handbook of proteolytic enzymes., London: Academics Press, 1998. 1666 p.

BELLO, C. A.; HERMOGENES, A. L. N.; MAGALHAES, A.; VEIGA, S. S.; GREMSKI, L. H.; RICHARDSON, M.; SANCHEZ, E. F. Isolation and biochemical characterization of a fibrinolytic proteinase from Bothrops leucurus (white-tailed jararaca) snake venom. Biochimie, v. 88, p. 189-200, 2006.

BERGER, M.; PINTO, A. F.; GUIMARÃES, J. A. Purification and functional characterization of bothrojaractivase, a prothrombin-activating metalloproteinase isolated from Bothrops jararaca snake venom. Toxicon, v. 51, p. 488-501, 2008.

BHAKDI, S.; KÄFLEIN, R.; HALSTENSEN, T. S.; HUGO, F.; PREISSNER, K. T.; MOLLNES, T. E. Complement S-protein (vitronectin) is associated with cytolytic membrane-bound C5b-9 complexes. Clin. Exp. Immunol., v. 74, p. 459-64, 1988.

BRADFORD, M. M. A rapid and sensitive method for the quantitation of microgram quantities of protein utilizing the principle of protein-dye binding. Anal. Biochem., v. 72, p. 248-54, 1976.

BURNETTE, W. N. "Western blotting": electrophoretic transfer of proteins from sodium dodecyl sulfate--polyacrylamide gels to unmodified nitrocellulose and radiographic detection with antibody and radioiodinated protein A. Anal. Biochem., v. 112, p. 195-203, 1981.

BJARNASON, J. B.; FOX, J. W. Characterization and substrate site mapping of two hemorragic zinc protease from Crotalus atrox. In: PIRKLE, H. and MARKLAND, F. S., Jr. (Ed.) Hematology and Animal Venoms. New York: Marcel Dkker, Inc., 1988. p. 457-477.

BJARNASON, J. B., FOX, J. W. Snake venom metalloendopeptidases: reprolysins. Methods Enzymol., v. 248, p. 345-368, 1995.

BLACK, R. A.; RAUCH, C. T.; KOZLOSKY, C. J.; PESCHON, J. J.; SLACK, J. L.; WOLFSON, M. F.; CASTNER, B. J.; STOCKING, K. L.; REDDY, P.; SRINIVASAN, S.; NELSON, N.; BOIANI, N.; SCHOOLEY, K. A.; GERHART, M.; DAVIS, R.; FITZNER, J. N.; JOHNSON, R. S.; PAXTON, R. J.; MARCH, C. J.; CERRETTI, D. P. 
A metalloproteinase disintegrin that releases tumour-necrosis factor-alpha from cells. Nature, v. 385, p. 729-733, 1997.

BODE, W.; GOMIS-RÜTH, F. X.; STÖCKLER, W. Astacins, serralysins, snake venom and matrix metalloproteinases exhibit identical zinc-binding environments (HEXXHXXGXXH and Met-turn) and topologies and should be grouped into a common family, the 'metzincins'. FEBS Lett., v. 331, p. 134-140, 1993.

BOTOS, I.; SCAPOZZA, J. D.; FOX, J. W.; MEYER, E. F. Structure - based analysis of inhibitor binding to Ht-d. Acta. Crysi., v. D51, p. 597-604, 1995.

BHAKDI, S.; KÄFLEIN, R.; HALSTENSEN, T. S.; HUGO, F.; PREISSNER, K. T.; MOLLNES, T. E. Complement S-protein (vitronectin) is associated with cytolytic membrane-bound C5b-9 complexes. Clin. Exp. Immunol., v. 74, p. 459-464, 1988.

BREEN, E. C. Mechanical strain increases type I collagen expression in pulmonary fibroblasts in vitro. J. Appl. Physiol., v. 88, p. 203-9, 2000.

BROWN, J. C.; TIMPL, R. The collagen superfamily. Int. Arch. Allergy Immunol., v. 107, p. 484-490, 1995.

CALVETE, J. J.; MORENO-MURCIANO, M. P.; SANZ, L.; JÜRGENS, M.; SCHRADER, M.; RAIDA, M.; BENJAMIN, D. C.; FOX, J. W. The disulfide bond pattern of catrocollastatin $\mathrm{C}$, a disintegrin-like / cysteine-rich protein isolated from Crotalus atrox venom. Protein. Sci., v. 9, p. 1365-1373, 2000.

CHU, M. L.; ZHANG, R. Z.; PAN, T. C.; STOKES, D.; CONWAY, D.; KUO, H. J.; GLANVILLE, R.; MAYER, U.; MANN, K.; DEUTZMANN, R.; TIMPL, R. Mosaic structure of globular domains in the human type $\mathrm{VI}$ collagen oz3 chain: similarity to von Willebrand Factor, fibronectin, actin, salivary proteins and aprotinin type protease inhibitors. EMBO J., v. 9, p. 385-393, 1990.

COLIGE, A.; BESCHIN, A.; SAMYN, B.; GOEBELS, Y.; VAN BEEUMEN, J.; NUSGENS, B. V.; LAPIERE, C. M. Characterization and partial amino acid sequencing of a $107-\mathrm{kDa}$ procollagen I N-proteinase purified by affinity chromatography on immobilized type XIV collagen. J. Biol. Chem., v. 270, p. 1672416730, 1995.

DANIELSEN, C. C. Thermal stability of reconstituted collagen fibrils. Shrinkage characteristics upon in vitro maturation. Mech. Ageing. Dev. v. 15, p. 269-78, 1981. 
DAHLBICK, B.; PODACK, E. R. Characterization of human S protein, an inhibitor of the membrane attack complex of complement. Demonstration of a free reactive thiol group Biochemistry, v. 24, p. 2368-2374, 1985.

DAVIS, G. E.; SENGER, D. R. Endothelial extracellular matrix: biosynthesis, remodeling, and functions during vascular morphogenesis and neovessel stabilization. Circ. Res., v. 97, p. 1093-1107, 2005.

DESHIMARU, M.; OGAWA, T.; NAKASHIMA, K.; NOBUHISA, I.; CHIJIWA, T.; SHIMOHIGASHI, Y.; FUKUMAKI, Y.; NIWA, M.; YAMASHINA, I.; HATTORI, S.; OHNO, M. Accelerated evolution of crotalinae snake venom gland serine proteases. FEBS Lett., v. 97, p. 83-88, 1996.

DWEK, R. A.; EDGE, C. J.; HARVEY, D. J.; WORMALD, M. R.; PAREKH, R. B. Analysis of glycoprotein-associated oligosaccharides. Annu. Rev. Biochem., v. 62, p. 65-100, 1993.

ESCALANTE, T.; SHANNON, J.; MOURA-DA-SILVA, A. M.; GUTIÉRREZ, J. M.; FOX, J. W. Novel insights into capillary vessel basement membrane damage by snake venom hemorrhagic metalloproteinases: a biochemical and immunohistochemical study. Arch. Biochem. Biophys., v. 455, p. 144-153, 2006.

ESCREVENTE, C.; MORAIS, V. A.; KELLER, S.; SOARES, C. M.; ALTEVOGT, P.; COSTA, J. Functional role of $\mathrm{N}$-glycosylation from ADAM10 in processing, localization and activity of the enzyme. Biochim. Biophys. Acta., v. 1780, p. 905913, 2008.

ESTEVÃO-COSTA, M. I.; DINIZ, C. R.; MAGALHÃES, A.; MARKLAND, F. S.; SANCHEZ, E. F. Action of metalloproteinases mutalysin I and mutalysin II on several components of the hemostatic and fibrinolytic systems. Thrombosis Research, v. 99, p. 363-376, 2000.

FERNANDES, R. J.; HIROHATA, S.; ENGLE, J. M.; COLIGE, A.; COHN, D. H.; EYRE, D. R.; APTE, S. S. Procollagen II amino propeptide processing by ADAMTS3. Insights on dermatosparaxis. J. Biol. Chem., v. 276, p. 31502-31509, 2001.

FERNANDEZ, J. H.; SILVA, C. A.; ASSAKURA, M. T.; CAMARGO, A. C.; SERRANO, S. M. Molecular cloning, functional expression, and molecular modeling of bothrostatin, a new highly active disintegrin from Bothrops jararaca venom. Biochem. Biophys. Res. Commun., v. 329, p. 457-464, 2005. 
FOX, J. W.; MAYER, U.; NISCHT, R.; AUMAILLEY, M.; REINHARDT, D.; WIEDEMANN, H.; MANN, K.; TIMPL, R.; KRIEG, T.; ENGEL, J.; et al. Recombinant nidogen consists of three globular domains and mediates binding of laminin to collagen type IV. EMBO J., v. 10, p. 3137-3146. 1991.

FOX, J. W.; LONG, C. The ADAMs/MDC family of proteins and their relationships to the snake venom metalloproteinases. In: BAILEY, G., (Ed.). Snake Venom Enzymes. Ft. Collins, CO: Alaken Press, 1998. p.151-178.

FOX, J. W.; SERRANO, S. M. T. Structural considerations of the snake venom metalloproteinases, key members of the M12 reprolysin family of metalloproteinases. Toxicon, v. 45, p. 969-985, 2005.

FOX, J. W.; SERRANO, S. M. T. Exploring snake venom proteomes: multifaceted analyses for complex toxin mixtures. Proteomics, v. 8, p. 909-20, 2008a.

FOX, J. W.; SERRANO, S. M. T. Insights into and speculations about snake venom metalloproteinase (SVMP) synthesis, folding and disulfide bond formation and their contribution to venom complexity. The FEBS Journal, v. 275, p. 3016-30, 2008b.

FOX, J.; SERRANO, S. M. T. Timeline of key events in snake venom metalloproteinase research. J. Proteomics, 2009. In press.

GARCÍA, L. T.; PARREIRAS, E.; SILVA, L. T.; RAMOS, O. H.; CARMONA, A. K.; BERSANETTI, P. A.; SELISTRE-DE-ARAUJO, H. S. The effect of post-translational modifications on the hemorrhagic activity of snake venom metalloproteinases. Comp. Biochem. Physiol. C Toxicol. Pharmacol., v. 138, p. 23-32, 2004.

GAULTIER, A.; COUSIN, H.; DARRIBÈRE, T.; ALFANDARI, D. ADAM13 disintegrin and cysteine-rich domains bind to the second heparin-binding domain of fibronectin. J._Biol. Chem., v. 277, p. 23336-23344, 2002.

GELSE, K.; PÖSCHL, E.; AIGNER, T. Collagens-structure, function, and biosynthesis. Adv. Drug Deliv. Rev., v. 55, p. 1531-1546, 2003.

GONÇALVES, L. R.; MARIANO, M. Local haemorrhage induced by Bothrops jararaca venom: relationship to neurogenic inflammation. Mediators Inflamm., v. 9, p. 101-107, 2000. 
GOWDA, D. C.; JACKSON, C. M.; KURZBAN, G. P.; MCPHIE, P.; DAVIDSON, E. A. Core sugar residues of the $\mathrm{N}$-linked oligosaccharides of Russell's viper venom factor X-activator maintain functionally active polypeptide structure. Biochemistry, v. 35, p. 5833-5837, 1996.

GRAMS, F.; HUBER, R.; KRESS, L. F.; MORODER, L.; BODE, W. Activation of snake venom metalloproteinases by a cysteine switch-like mechanism. FEBS Lett., v. 335, p. 76-80, 1993.

GUTIÉRREZ, J. M.; LOMONTE, B. Local tissue damage induced by Bothrops snake venoms: a review. Men. Instituto Butantan, v. 51, p. 211-223, 1989.

GUTIÉRREZ, J. M.; RUCAVADO, A.; ESCALANTE, T.; DÍAZ, C. Hemorrhage induced by snake venom metalloproteinases: biochemical and biophysical mechanisms involved in microvessel damage. Toxicon., v. 45, p. 997-1011, 2005.

HAMAKO, J.; MATSUI, T.; NISHIDA, S.; NOMURA, S.; FUJIMURA, Y.; ITO, M.; OZEKI, Y.; TITANI K. Purification and characterization of kaouthiagin, a von Willebrand factor-binding and -cleaving metalloproteinase from Naja kaouthia cobra venom. Thromb. Haemost., v. 80, p. 499-505, 1998.

HANNA, S. L.; SHERMAN, N. E.; KINTER, M. T.; GOLDBERG, J. B. Comparison of proteins expressed by Pseudomonas aeruginosa strains representing initial and chronic isolates from a cystic fibrosis patient: an analysis by 2-D gel electrophoresis and capillary column liquid chromatography-tandem mass spectrometry. Microbiology, v. 146, p. 2495-2508, 2000.

HAYMAN, E. G.; PIERSCHBACHER, M. D.; OHGREN, Y.; RUOSLAHTI, E. Serum spreading factor (vitronectin) is present at the cell surface and in tissues. Proc. Natl. Acad. Sci., v. 80, p. 4003-4007, 1983.

HARRIS, J. R.; REIBER, A. Influence of saline and $\mathrm{pH}$ on collagen type I fibrillogenesis in vitro: fibril polymorphism and colloidal gold labelling. Micron., v. 38, p. 513-521, 2007.

HYNES, R. O. Fibronectins. New York: Springer-Verlag, 1990. 546 p.

HOOPER, N. M.; KARRAN, E. H.; TURNER, A. J. Membrane protein secretases. Biochem. J., v. 321, p. 265-279, 1997. 
HUANG, K. F.; HUNG, C. C.; WU, S. H.; CHIOU, S. H. Characterization of three endogenous peptide inhibitors for multiple metalloproteinases with fibrinogenolytic activity from the venom of Taiwan habu (Trimeresurus mucrosquamatus). Biochem. Biophys. Res. Commun., v. 248, p. 562-568, 1998.

IGARASHI, T.; ARAKI, S.; MORI, H.; TAKEDA, S. Crystal structures of catrocollastatin/VAP2B reveal a dynamic, modular architecture of ADAM/adamalysin/reprolysin family proteins. FEBS Lett., v. 581, p. 2416-2422, 2007.

IZUMI, Y.; HIRATA, M.; HASUWA, H.; IWAMOTO, R.; UMATA, T.; MIYADO, K.; TAMAI, Y.; KURISAKI, T.; SEHARA-FUJISAWA, A.; OHNO, S.; MEKADA, E. A metalloprotease-disintegrin, MDC9/meltrin-gamma/ADAM9 and PKCdelta are involved in TPA-induced ectodomain shedding of membrane-anchored heparinbinding EGF-like growth factor. EMBO J., v. 17, p. 7260-7272, 1998.

JANDER, R.; RAUTERBERG, J.; GLANVILLE, R. W. Further characterisation of the three polypeptide chains of bovine and human short chain collagen (intima collagen).

Eur. J. Biochem., v. 133, p. 39-46, 1983.

JIA, L. G.; WANG, X. M.; SHANNON, J. D.; BJARNASON, J. B.; FOX, J. W. Function of disintegrin-like/cysteine-rich domains of atrolysin $A$. Inhibition of platelet aggregation by recombinant protein and peptide antagonists. J. Biol. Chem., v. 272, p. 13094-13102, 1997.

JIA, L. G.; WANG, X. M.; SHANNON, J. D.; BJARNASON, J. B.; FOX, J. W. Inhibition of platelet aggregation by the recombinant cysteine-rich domain of the hemorrhagic snake venom metalloproteinase, atrolysin A. Arch. Biochem. Biophys., v. 373, p. 281-286, 2000.

KAMIGUTI, A. S.; SLUPSKY, J. R.; ZUZEL, M.; HAY, C. R. Properties of fibrinogen cleaved by jararhagin, a metalloproteinase from the venom of Bothrops jararaca. Thromb. Haemost., v. 72, p. 244-249, 1994.

KAMIGUTI, A. S.; HAY, C. R.; THEAKSTON, R. D.; ZUZEL, M. Insights into the mechanism of haemorrhage caused by snake venom metalloproteinases. Toxicon, v. 34, p. 627-642, 1996.

KAMIGUTI, A. S.; GALLAGHER, P.; MARCINKIEWICZ, C.; THEAKSTON, R. D.; ZUZEL, M.; FOX, J. W. Identification of sites in the cysteine-rich domain of the class P-III snake venom metalloproteinases responsible for inhibition of platelet function. FEBS Lett., v. 549, p. 129-134, 2003. 
KARLSSON, E. Chemistry of protein toxins in snake venom. In: LEE, C. Y. (Ed). Handbook of Experimental Pharmacology. Berlin: Springer-Verlag, 1979. p. 159212.

KIM, T.; OH, J.; WOO, J. M.; CHOI, E.; IM, A. H.; YOO, Y. J.; KIM, D. H.; NISHIMURA, H.; CHO, C. Expression and Relationship of Male Reproductive ADAMs in Mouse Biol. Reprod., v. 74, p. 744-750, 2006.

KIMURA, N.; TOYOSHIMA, T.; KOJIMA, T.; SHIMANE, M. Entactin-2: a new member of basement membrane protein with high homology to entactin/nidogen. Exp. Cell Res., v. 241, p. 36-45, 1998.

KUO, H. J.; MASLEN, C. L.; KEENE, D. R.; GLANVILLE, R. W. Type VI collagen anchors endothelial basement membranes by interacting with type IV collagen. $\mathbf{J}$. Biol. Chem., v. 272, p. 26522-26529, 1997.

LAEMMLI, U. K. Cleavage of structural proteins during the assembly of the head of bacteriophage T4. Nature, v. 227, p. 680-685, 1970.

LAING, G. D.; MOURA-DA-SILVA, A. M. Jararhagin and its multiple effects on hemostasis. Toxicon, v. 45:987-996, 2005.

LEVY, G. G.; NICHOLS, W. C.; LIAN, E. C.; FOROUD, T.; MCCLINTICK, J. N.; MCGEE, B. M.; YANG, A. Y.; SIEMIENIAK, D. R.; STARK, K. R.; GRUPPO, R.; SARODE, R.; SHURIN, S. B.; CHANDRASEKARAN, V.; STABLER, S. P.; SABIO, H.; BOUHASSIRA, E. E.; UPSHAW, J. D. JR.; GINSBURG, D.; TSAI, H. M. Mutations in a member of the ADAMTS gene family cause thrombotic thrombocytopenic purpura. Nature, v. 413, p. 488-494, 2001.

LIU, C. Z.; HUANG, T. F. Crovidisin, a collagen-binding protein isolated from snake venom of Crotalus viridis, prevents platelet-collagen interaction. Arch. Biochem. Biophys., v. 337, p. 291-299, 1997.

LOMONTE, B.; GUTIÉRREZ, J. M.; BORKOW, G.; OVADIA, M.; TARKOWSKI, A.; HANSON, L. A. Activity of hemorrhagic metalloproteinase $\mathrm{BaH}-1$ and myotoxin II from Bothrops asper snake venom on capillary endothelial cells in vitro. Toxicon, v. 32, p. 505-510, 1994.

MAKOGONENKO, E.; TSURUPA, G.; INGHAM, K.; MEDVED, L. Interaction of fibrin(ogen) with fibronectin: further characterization and localization of the fibronectin-binding site. Biochemistry, v. 41, p. 7907-7913, 2002. 
MANABE, R.; OHE, N.; MAEDA, T.; FUKUDA, T.; SEKIGUCHI, K. Modulation of celladhesive activity of fibronectin by the alternatively spliced EDA segment. J. Cell Biol., v. 139, p. 295-307, 1997.

MANDELBAUM, F. R.; REICHL, A. P.; ASSAKURA, M. T. Isolation and characterization of a proteolytic enzyme from the venom of the snake Bothrops jararaca (jararaca). Toxicon, v. 20, p. 955-972, 1982.

MANDELBAUM, F. R.; SERRANO M. T. S.; SAKURADA, J. K.; RANGEL, H. A.; ASSAKURA, M. T. Immunological comparison of hemorrhagic principles present in venoms of the crotalinae and viperinae subfamilies. Toxicon, v. 27, p. 169-177, 1989.

MARCUSSI, S.; BERNARDES, C. P.; SANTOS-FILHO, N. A.; MAZZI, M. V.; OLIVEIRA, C. Z.; IZIDORO, L. F.; FULY, A. L.; MAGRO, A. J.; BRAZ, A. S.; FONTES, M. R.; GIGLIO, J. R.; SOARES, A. M. Molecular and functional characterization of a new non-hemorrhagic metalloprotease from Bothrops jararacussu snake venom with antiplatelet activity. Peptides, v. 28, p. 2328-2339, 2007.

MARQUES-PORTO, R.; LEBRUN, I.; PIMENTA, D. C. Self-proteolysis regulation in the Bothrops jararaca venom: the metallopeptidases and their intrinsic peptidic inhibitor. Comp. Biochem. Physiol. C. Toxicol. Pharmacol. v. 147, p. 424-433, 2008.

MATSUDA, A. A distribution of fibronectin in plasma and liver disease. Clin. Chim. Acta. v. 118, p. 191-199, 1982.

MAZZUCATO, M.; SPESSOTTO, P.; MASOTTI, A.; DE APPOLLONIA, L.; COZZI, M. R.; YOSHIOKA, A.; PERRIS, R.; COLOMBATTI, A.; DE MARCO, L. Identification of domains responsible for von Willebrand factor type VI collagen interaction mediating platelet adhesion under high flow. J. Biol. Chem., v. 274, p. 3033-3041, 1999.

MCKEE, P. A.; ROGERS, L. A.; MARLER, E.; HILL, R. L. The subunit polypeptides of human fibrinogen. Arch. Biochem. Biophys., v. 116, p. 271-279, 1966.

MENEZES, M. C.; FURTADO, M. F.; TRAVAGLIA-CARDOSO, S. R.; CAMARGO, A. C.; SERRANO, S. M. Sex-based individual variation of snake venom proteome among eighteen Bothrops jararaca siblings. Toxicon, v. 47, p. 304-312, 2006. 
MENEZES, M. C.; PAES LEME, A. F.; MELO, R. L.; SILVA, C. A.; DELLA CASA, M.; BRUNI, F. M.; LIMA, C.; LOPES-FERREIRA, M.; CAMARGO, A. C.; FOX, J. W.; SERRANO, S. M. Activation of leukocyte rolling by the cysteine-rich domain and the hyper-variable region of HF3, a snake venom hemorrhagic metalloproteinase. FEBS Lett., v. 582, p. 3915-3921, 2008.

MINER, J. H.; YURCHENCO, P. D. Laminin functions in tissue morphogenesis. Annu. Rev. Cell Dev. Biol., v. 20, p. 255-284, 2004.

MOREIRA, L.; GUTIÉRREZ, J. M.; BORKOW, G.; OVADIA, M. Ultrastructural alterations in mouse capillary blood vessels after experimental injection of venom from the snake Bothrops asper (Terciopelo). Exp. Mol. Pathol., v. 57, p. 124-133, 1992.

MOREIRA, L.; BORKOW, G.; OVADIA, M.; GUTIÉRREZ, J. M. Pathological changes induced by $\mathrm{BaH1}$, a hemorrhagic proteinase isolated from Bothrops asper (Terciopelo) snake venom, on mouse capillary blood vessels. Toxicon., v. 32, p. 976-987, 1994.

MORTZ, E.; KROGH, T. N.; VORUM, H.; GORG, A. Improved silver staining protocols for high sensitivity protein identification using matrix-assisted laser desorption/ionization-time of flight analysis. Proteomics, v. 1, p. $1359-1363,2001$.

MOSS, M. L.; JIN, S. L.; MILLA, M. E.; BICKETT, D. M.; BURKHART, W.; CARTER, H. L.; CHEN, W. J.; CLAY, W. C.; DIDSBURY, J. R.; HASSLER, D.; HOFFMAN, C. R.; KOST, T. A.; LAMBERT, M. H.; LEESNITZER, M. A.; MCCAULEY, P.; MCGEEHAN, G.; MITCHELL, J.; MOYER, M.; PAHEL, G.; ROCQUE, W.; OVERTON, L. K.; SCHOENEN, F.; SEATON, T.; SU, J. L.; BECHERER, J. D., et al. Cloning of a disintegrin metalloproteinase that processes precursor tumour-necrosis factor-alpha. Nature, v. 385, p. 733-736, 1997.

MOURA-DA-SILVA, A. M.; MARCINKIEWICZ, C.; MARCINKIEWICZ, M.; NIEWIAROWSKI, S. Selective recognition of alpha2beta1 integrin by jararhagin, a Metalloproteinase/disintegrin from Bothrops jararaca venom. Thromb. Res., v. 102, p. 153-159, 2001.

MOURA-DA-SILVA, A. M.; DELLA-CASA, M. S.; DAVID, A. S.; ASSAKURA, M. T.; BUTERA, D.; LEBRUN, I.; SHANNON, J. D.; SERRANO, S. M.; FOX, J. W. Evidence for heterogeneous forms of the snake venom metalloproteinase jararhagin: a factor contributing to snake venom variability. Arch. Biochem. Biophys., v.409, p. 395401, 2003. 
MOURA-DA-SILVA, A. M.; RAMOS, O. H.; BALDO, C.; NILAND, S.; HANSEN, U.; VENTURA, J. S.; FURLAN, S.; BUTERA, D.; DELLA-CASA, M. S.; TANJONI, I.; CLISSA, P. B.; FERNANDES, I.; CHUDZINSKI-TAVASSI, A. M.; EBLE, J. A. Collagen binding is a key factor for the hemorrhagic activity of snake venom metalloproteinases. Biochimie, v. 90, p.484-492, 2008.

MUNIZ, J. R.; AMBROSIO, A. L.; SELISTRE-DE-ARAUJO, H. S.; COMINETTI, M. R.; MOURA-DA-SILVA, A. M.; OLIVA, G.; GARRATT, R. C.; SOUZA, D. H. The three-dimensional structure of bothropasin, the main hemorrhagic factor from Bothrops jararaca venom: insights for a new classification of snake venom metalloprotease subgroups. Toxicon, v. 52, p.807-816, 2008.

NAKASHIMA, K.; NOBUHISA, I.; DESHIMARU, M.; NAKAI, M.; OGAWA, T.; SHIMOHIGASHI, Y.; FUKUMAKI, Y.; HATTORI, M.; SAKAKI, Y.; HATTORI, S., et al. Accelerated evolution in the protein-coding regions is universal in crotalinae snake venom gland phospholipase A2 isozyme genes. Proc. Natl. Acad. Sci., v. 92, p. 5605-5609, 1995.

NISHIMURA, H.; CHO, C.; BRANCIFORTE, D. R.; MYLES, D. G.; PRIMAKOFF, P. Analysis of loss of adhesive function in sperm lacking cyritestin or fertilin beta. Dev. Biol., v. 233, p. 204-213, 2001.

NISSINEN, M.; VUOLTEENAHO, R.; BOOT-HANDFORD, R.; KALLUNKI, P.; TRYGGVASON, K. Primary structure of the human laminin A chain. Limited expression in human tissues. Biochem. J., v. 276, p. 369-379, 1991.

OPDENAKKER, G.; RUDD, P. M.; PONTING, C. P.; DWEK, R. A. Concepts and principles of glycobiology. FASEB J., v. 7, p. 1330-1337, 1993.

OUYANG, C.; TENG, C. M.; HUANG, T. F. Characterization of snake venom components acting on blood coagulation and platelet function. Toxicon, v. 30, p. 945-966, 1992.

PAES LEME, A. F.; PREZOTO, B. C.; YAMASHIRO, E. T.; BERTHOLIM, L.; TASHIMA, A. K.; KLITZKE, C. F.; CAMARGO, A. C.; SERRANO, S. M. T. Bothrops protease $A$, a unique highly glycosylated serine proteinase, is a potent, specific fibrinogenolytic agent. J. Thromb. Haemost., v. 6, p. 1363-1372, 2008.

PAINE, M. J.; DESMOND, H. P.; THEAKSTON, R. D.; CRAMPTON, J. M. Purification, cloning, and molecular characterization of a high molecular weight hemorrhagic metalloprotease, jararhagin, from Bothrops jararaca venom. Insights into the disintegrin gene family. J. Biol. Chem., v. 267, p. 22869-22876, 1992. 
PETERSEN, T. E.; THOGERSEN, H. C.; SKORSTENGAARD, K.; IBE-PEDERSEN, K.; SAHL, P.; SOTTRUP-JENESEN, L.; MAGNUSSON, S. Partial primary structure of bovine plasma fibronectin: three types of internal homology. Proc. Natl. Acad. Sci., v. 80, p. 137-141, 1983.

PORTER, S.; CLARK, I. M.; KEVORKIAN, L.; EDWARDS, D. R. The ADAMTS metalloproteinases. Biochem. J., v. 386, p. 15-27. 2005.

PREISSNER, K. T.; HOLZHÜTER, S.; JUSTUS, C.; MÜLLER-BERGHAUS, G. Identification of and partial characterization of platelet vitronectin: evidence for complex formation with platelet-derived plasminogen activator inhibitor-1. Blood, v. 74 , p. 1989-1996, 1989.

RAMOS, O. H.; CARMONA, A. K.; SELISTRE-DE-ARAUJO, H. S. Expression, refolding, and in vitro activation of a recombinant snake venom pro-metalloprotease. Protein. Expr. Purif., v. 28, p. 34-41, 2003.

RAND, J. H.; WU, X. X.; POTTER, B. J.; USON, R. R.; GORDON, R. E. Colocalization of von Willebrand factor and type VI collagen in human vascular subendothelium. Am. J. Pathol., v. 142, p. 843-850, 1993.

RAWLINGS, N. D.; MORTON, F. R.; KOK, C. Y.; KONG, J.; BARRETT, A. J. MEROPS: the peptidase database. Nucleic. Acids. Res., v. 36, D320-D325, 2008. Available from: http://merops.sanger.ac.uk/index.htm/. Acess in: 05 dez. 2008.

RIBEIRO, L.A.; ALBUQUERQUE, M.J.; PIRES-DE-CAMPOS, V. A. F.; KATZ, G.; TAKAOKA, N. Y.; LEBRÃO, M. L.; JORGE, M. T. Óbitos por serpentes peçonhentas no Estado de São Paulo: avaliação de 43 casos, 1988/1993. Rev. Assoc. Med. Bras., v. 44, p. 312-318, 1998.

RICARD-BLUM, S.; DUBLET, B.; VAN DER REST, M. Unconventional Collagens Types VI, VII, VIII, IX, X, XII, XIV, XVI and XIX. London: Oxford University Press, 2000. 176 p.

ROBEVA, A.; POLITI, V.; SHANNON, J. D.; BJARNASON, J. B.; FOX, J. W. Synthetic and endogenous inhibitors of snake venom metalloproteinases. Biomed. Biochim. Acta., v. 50: 769-773, 1991.

RUCAVADO, A.; FLORES-SANCHEZ, E.; FRANCESCHI, A.; MAGALHAES, A.; GUTIERREZ, J. M. Characterization of the local tissue damage induced by LHF-II, a 
metalloproteinase with weak hemorrhagic activity isolated from Lachesis muta muta snake venom Toxicon, v. 37, p. 1297-1312, 1999.

SANO-MARTINS, I. S.; SANTORO, M. L.; CASTRO, S. C.; FAN, H. W.; CARDOSO, J. L.; THEAKSTON, R. D. Platelet aggregation in patients bitten by the Brazilian snake Bothrops jararaca. Thromb. Res., v. 87, p. 183-195, 1997.

SARRATT, K. L.; CHEN, H.; KAHN, M. L.; HAMMER, D. A. Platelet receptor glycoprotein VI-mediated adhesion to type I collagen under hydrodynamic flow. Ann. Biomed. Eng., v. 32, p. 970-976, 2004.

SARRATT, K. L.; CHEN, H.; ZUTTER, M. M.; SANTORO, S. A.; HAMMER, D. A.; KAHN, M. L. GPVI and $\alpha 2 \beta 1$ play independent critical roles during platelet adhesion and aggregate formation to collagen under flow._Blood, v. 106, p. 1268-1277, 2005.

SEALS, D. F.; COURTNEIDGE, S. A. The ADAMs family of metalloproteases: multidomain proteins with multiple functions. Genes Dev., v. 17, p. 7-30, 2003.

SCHERAGA, H. A.; LASKOWSKI M. Jr. The Fibrinogen-Fibrin Conversion. Advances in Protein Chemistry, v. 12, p. 1-131, 1957.

SCHERAGA, H. A. The thrombin-fibrinogen interaction. Biophys. Chem., v. 112, p. 117-130, 2004.

SCHLÖNDORFF, J.; BLOBEL, C. P. Metalloprotease-disintegrins: modular proteins capable of promoting cell-cell interactions and triggering signals by proteinectodomain shedding. J. Cell Sci., v. 112, p. 3603-3617, 1999.

SERRANO, S. M.; JIA, L. G.; WANG, D.; SHANNON, J.D.; FOX, J. W. Function of the cysteine-rich domain of the haemorrhagic metalloproteinase atrolysin A: targeting adhesion proteins collagen I and von Willebrand factor. Biochem. J., v. 391, p. 6976, 2005.

SERRANO, S. M.; MAROUN, R. C. Snake venom serine proteinases: sequence homology vs. substrate specificity, a paradox to be solved. Toxicon, v. 45, p. 11151132, 2005.

SERRANO, S. M.; KIM, J.; WANG, D.; DRAGULEV, B.; SHANNON, J. D.; MANN, H. H.; VEIT, G.; WAGENER, R.; KOCH, M.; FOX, J. W. The cysteine-rich domain of 
snake venom metalloproteinases is a ligand for von Willebrand factor A domains: role in substrate targeting. J. Biol. Chem., v. 281, p. 39746-39756, 2006.

SERRANO, S. M.; WANG, D.; SHANNON, J. D.; PINTO, A. F.; POLANOWSKAGRABOWSKA, R. K.; FOX, J. W. Interaction of the cysteine-rich domain of snake venom metalloproteinases with the A1 domain of von Willebrand factor promotes site-specific proteolysis of von Willebrand factor and inhibition of von Willebrand factor-mediated platelet aggregation. FEBS J., v. 274, p. 3611-3621, 2007.

SHIMOKAWA, K. I.; SHANNON, J. D.; JIA, L. G.; FOX, J. W. Sequence and biological activity of catrocollastatin-C: a disintegrin-like/cysteine-rich two-domain protein from Crotalus atrox venom. Arch. Biochem. Biophys., v. 343, p. 35-43, 1997.

SILVA, M. B.; SCHATTNER, M.; RAMOS, C. R.; JUNQUEIRA-DE-AZEVEDO, I. L.; GUARNIERI, M. C.; LAZZARI, M. A.; SAMPAIO, C. A.; POZNER, R. G.; VENTURA, J.S.; HO, P. L.; CHUDZINSKI-TAVASSI, A. M. A prothrombin activator from Bothrops erythromelas (jararaca-da-seca) snake venom: characterization and molecular cloning. Biochen. J., v. 369, p. 129-139, 2003.

SILVA, C. A.; ZULIANI, J. P.; ASSAKURA, M. T.; MENTELE, R.; CAMARGO, A. C.; TEIXEIRA, C. F.; SERRANO, S. M. Activation of alpha(M)beta(2)-mediated phagocytosis by HF3, a P-III class metalloproteinase isolated from the venom of Bothrops jararaca. Biochem. Biophys. Res. Commun., v. 322, p. 950-956, 2004.

SOEJIMA, K.; MIMURA, N.; HIRASHIMA, M.; MAEDA, H.; HAMAMOTO, T.; NAKAGAKI, T.; NOZAKI, C. A novel human metalloprotease synthesized in the liver and secreted into the blood: possibly, the von Willebrand factor-cleaving protease? J. Biochem., v. 130, p. 475-480, 2001.

SOUZA, D. H.; IEMMA, M. R.; FERREIRA, L. L.; FARIA, J. P.; OLIVA, M. L.; ZINGALI, R. B.; NIEWIAROWSKI, S.; SELISTRE-DE-ARAUJO, H. S. The disintegrinlike domain of the snake venom metalloprotease alternagin inhibits alpha2beta1 integrin-mediated cell adhesion. Arch. Biochem. Biophys., v. 384, p. 341-350, 2000.

STÖCKER, W.; BODE, W. Structural features of a superfamily of zincendopeptidases: the metzincins. Curr. Opin. Struct. Biol., v. 5, p. 383-390, 1995.

SUKI, B.; BATES, J. H. Extracellular matrix mechanics in lung parenchymal diseases. Respir. Physiol. Neurobiol., v. 163, p. 33-43, 2008. 
SUZUKI, S.; OLDBERG, A.; HAYMAN, E. G.; PIERSCHBACHER, M. D.; RUOSLAHTI, E. Complete amino acid sequence of human vitronectin deduced from cDNA. Similarity of cell attachment sites in vitronectin and fibronectin. EMBO J., v. 4, p. 2519-2524, 1985.

SWENSON, S.; MARKLAND, F. S. JR. Snake venom fibrin(ogen)olytic enzymes. Toxicon, v. 45, p.1021-1039, 2005.

TANJONI, I.; BUTERA, D.; SPENCER, P. J.; TAKEHARA, H. A.; FERNANDES, I.; MOURA-DA-SILVA, A. M. Phylogenetic conservation of a snake venom metalloproteinase epitope recognized by a monoclonal antibody that neutralizes hemorrhagic activity. Toxicon, v. 42, p. 809-816, 2003.

TAKEDA, S.; IGARASHI, T.; MORI, H.; ARAKI, S. Crystal structures of VAP1 reveal ADAMs' MDC domain architecture and its unique C-shaped scaffold. EMBO J., v. 25, p. 2388-2396, 2006.

TIMPL, R.; ROHDE, H.; ROBEY, P. G.; RENNARD, S. I.; FOIDART, J. M.; MARTIN, G. R. Laminin--a glycoprotein from basement membranes. J. Biol. Chem., v. 254, p. 9933-9937, 1979.

TIMPL, R. Macromolecular organization of basement membranes. Curr. Opin. Cell Biol., v. 8, p. 618-624, 1996.

TOLLEFSEN, D. M.; WEIGEL, C. J.; KABEER, M. H. The presence of methionine or threonine at position 381 in vitronectin is correlated with proteolytic cleavage at arginine 379. J. Biol. Chem., v. 265, p. 9778-9781, 1990.

TORTORELlA, M. D.; MALFAIT, A. M.; DECCICO, C.; ARNER, E. The role of ADAM-TS4 (aggrecanase-1) and ADAM-TS5 (aggrecanase-2) in a model of cartilage degradation. Osteoarthr. Cartil., v. 9, p. 539-552, 2001.

TRELSTAD, R. L.; HAYASHI, K.; GROSS, J. Collagen fibrillogenesis: Intermediate aggregates and suprafibrillar order. Proc. Natl. Acad. Sci. USA., v. 73, p. 40274031, 1976.

USAMI, Y.; FUJIMURA, Y.; MIURA, S.; SHIMA, H.; YOSHIDA, E.; YOSHIOKA, A.; HIRANO, K.; SUZUKI, M.; TITANI, K. A 28 kDa-protein with disintegrin-like structure (jararhagin-C) purified from Bothrops jararaca venom inhibits collagen- and ADPinduced platelet aggregation. Biochem. Biophys. Res. Commun., v. 201, p. 331339, 1994. 
VARKI A. Biological roles of oligosaccharides: all of the theories are correct Glycobiology, v. 3, p. 97-130, 1993.

VOSS, B.; ALLAM, S.; RAUTERBERG, J.; ULLRICH, K.; GIESELMANN, V.; VON FIGURA, K. Primary cultures of rat hepatocytes synthesize fibronectin. Biochem. Biophysis. Res. Commun., v. 90, p. 1348-1354, 1979.

WANG, W. M.; LEE, S.; STEIGLITZ, B. M.; SCOTT, I. C.; LEBARES, C. C.; ALLEN, M. L.; BRENNER, M. C.; TAKAHARA, K.; GREENSPAN, D. S. Transforming growth factor-beta induces secretion of activated ADAMTS-2. A procollagen III N-proteinase. J. Biol. Chem., v. 278, p. 19549-19557, 2003.

WARSHAWSKY, H.; HADDAD, A.; GONCALVES, R. P.; VALERI, V.; DE LUCCA, F. $L$. Fine structure of the venom gland epithelium of the South American rattlesnake and radioautographic studies of protein formation by the secretory cells. Am. J. Anat., v. 138, p. 79-119, 1973.

WYSS, D. F.; WAGNER, G. The structural role of sugars in glycoproteins. Curr. Opin. Biotechnol., v. 7, p. 409-416, 1996.

WOLFSBERG, T. G.; WHITE, J. M. ADAMSs in fertilization and development. Dev. Biol., v. 271, p. 389-401, 1996.

YOU, W. K.; JANG, Y. J.; CHUNG, K. H.; KIM, D. S. A novel disintegrin-like domain of a high molecular weight metalloprotease inhibits platelet aggregation. Biochem. Biophys. Res. Commun., v. 309, p. 637-642, 2003.

YURCHENCO, P. D.; RUBEN, G. C. Type IV collagen lateral associations in the EHS tumor matrix. Comparison with amniotic and in vitro networks. Am. J. Pathol., v. 132, p. 278-291, 1988.

ZHOU, Q.; SMITH, J. B.; GROSSMAN, M. H. Molecular cloning and expression of catrocollastatin, a snake-venom protein from Crotalus atrox (western diamondback rattlesnake) which inhibits platelet adhesion to collagen. Biochem. J., v. 307, p. 411417, 1995.

ZOLKIEWSKA, A. Disintegrin-like/Cysteine-Rich Region of ADAM 12 is an Active Cell Adhesion Domain. Exp. Cell Res., v. 252, p. 423-431, 1999. 